NBER WORKING PAPER SERIES

FINANCIAL CRASH, COMMODITY PRICES AND GLOBAL IMBALANCES

\author{
Ricardo J. Caballero \\ Emmanuel Farhi \\ Pierre-Olivier Gourinchas \\ Working Paper 14521 \\ http://www.nber.org/papers/w14521 \\ NATIONAL BUREAU OF ECONOMIC RESEARCH \\ 1050 Massachusetts Avenue \\ Cambridge, MA 02138 \\ December 2008
}

We thank Kathryn Dominguez, Doug Elmendorf, Carmen Reinhart, and Larry Summers for their comments and Gabriel Chodorow-Reich for excellent research assistance. Ricardo Caballero and Pierre-Olivier Gourinchas thank the NSF for financial support. Pierre-Olivier Gourinchas acknowledges the support of the Coleman-Fung Risk Management Research Center. First draft: July 2008. The views expressed herein are those of the author(s) and do not necessarily reflect the views of the National Bureau of Economic Research.

NBER working papers are circulated for discussion and comment purposes. They have not been peerreviewed or been subject to the review by the NBER Board of Directors that accompanies official NBER publications.

(C) 2008 by Ricardo J. Caballero, Emmanuel Farhi, and Pierre-Olivier Gourinchas. All rights reserved. Short sections of text, not to exceed two paragraphs, may be quoted without explicit permission provided that full credit, including () notice, is given to the source. 
Financial Crash, Commodity Prices and Global Imbalances

Ricardo J. Caballero, Emmanuel Farhi, and Pierre-Olivier Gourinchas

NBER Working Paper No. 14521

December 2008

JEL No. F3

\section{ABSTRACT}

In this paper we argue that the persistent global imbalances, the subprime crisis, and the volatile oil and asset prices that followed it, are tightly interconnected. They all stem from a global environment where sound and liquid financial assets are in scarce supply.

Ricardo J. Caballero

MIT

Department of Economics

Room E52-373a

Cambridge, MA 02142-1347

and NBER

caball@mit.edu

Emmanuel Farhi

Harvard University

Department of Economics

Littauer Center

Cambridge, MA 02138

and NBER

efarhi@harvard.edu
Pierre-Olivier Gourinchas

University of California, Berkeley

693 Evans Hall, \#3880

Economics Department

Berkeley, CA 94720-3880

and NBER

pog@econ.berkeley.edu 


\title{
Financial Crash, Commodity Prices and Global Imbalances
}

\author{
Ricardo J. Caballero Emmanuel Farhi Pierre-Olivier Gourinchas*
}

This version: November 17, 2008

In this paper we argue that the persistent global imbalances, the subprime crisis, and the volatile oil and asset prices that followed it, are tightly interconnected. They all stem from a global environment where sound and liquid financial assets are in scarce supply.

Our story goes as follows: Global asset scarcity led to large capital flows toward the U.S. and to the creation of asset bubbles that eventually crashed. The crash in the real estate market was particularly complex from the point of view of asset shortages since it compromised the whole financial sector, and by so doing, closed many of the alternative saving vehicles. Thus, in its first phase, the crisis exacerbated the shortage of assets in the world economy, which triggered a partial recreation of the bubble in commodities and oil markets in particular. The latter led to an increase in petrodollars seeking financial assets in the U.S. Thus, rather than the typical destabilizing role played by capital outflows during financial crises, petrodollar flows became a source of stability for the U.S. The second phase of the crisis is more conventional and began to emerge toward the end of the summer of 2008. It became apparent then that the financial crisis would permeate the real economy and sharply slow down global growth. This slowdown worked to reverse the tight commodity market conditions required for a bubble to develop, ultimately destroying the commodity bubble.

Let us now develop some of these steps, starting from the underlying structural force

\footnotetext{
${ }^{*}$ Respectively: MIT and NBER; Harvard and NBER; UC Berkeley and NBER. E-mails: caball@mit.edu, efarhi@harvard.edu,pog@berkeley.edu. Prepared for the September 2008 Brookings Papers on Economic Activity Conference. We thank Kathryn Dominguez, Doug Elmendorf, Carmen Reinhart, and Larry Summers for their comments and Gabriel Chodorow-Reich for excellent research assistance. Ricardo Caballero and Pierre-Olivier Gourinchas thank the NSF for financial support. Pierre-Olivier Gourinchas acknowledges the support of the Coleman-Fung Risk Management Research Center. First draft: July 2008.
} 


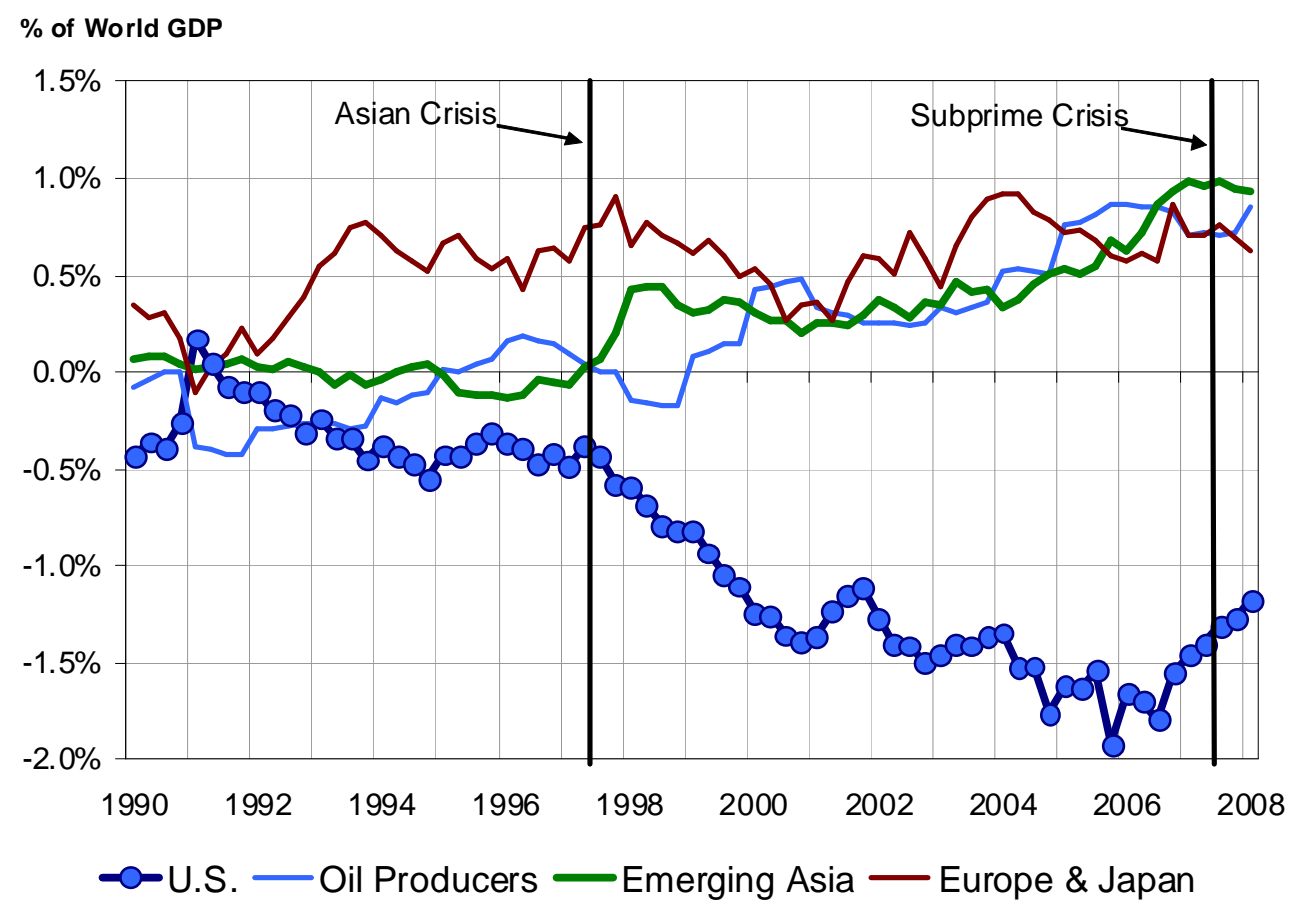

Figure 1: Global Imbalances (as a fraction of World GDP), 1990:1-2008:1. Data Sources: WDI, WEO, IFS \& OECD, authors' calculations.

fueling U.S. asset appreciation. Figure 1 displays the main patterns of global imbalances since 1990. In particular, it shows the current account of the U.S., Europe \& Japan, emerging Asia, and oil producing economies, relative to world GDP. ${ }^{1}$ The facts are well-known: Starting in 1991, the U.S. current account deficit worsened continuously, reaching 6.4 percent of U.S. GDP in the fourth quarter of 2005, then stabilizing back to 5 percent of GDP by early 2008. The counterpart of the U.S. deficits, initially due to Japan and Europe, were bolstered by emerging Asia and commodity producing countries after 1997.

In Caballero, Farhi and Gourinchas (2008) we showed how this build-up in "global imbalances" could be understood as the consequence of asymmetries in financial development and growth prospects across different regions of the world. In particular, we argued that the Emerging Market (EM) crises at the end of the 1990s, the subsequent rapid growth of China and other East Asian economies, and the associated rise in commodity prices in

\footnotetext{
${ }^{1}$ The sample of European countries includes: Austria, Belgium, France, Germany, Ireland, Italy, Netherlands, Spain, Denmark, Iceland, Sweden, and Switzerland. Oil producing countries include: Canada, Norway, Mexico, Venezuela, Russia, Saudi Arabia, Iran, Nigeria, Kuwait, Libya, Oman and Bahrain. Asian countries include: South Korea, China, Taiwan, Hong Kong, Indonesia, Malaysia, the Philippines, Singapore, and Thailand.
} 


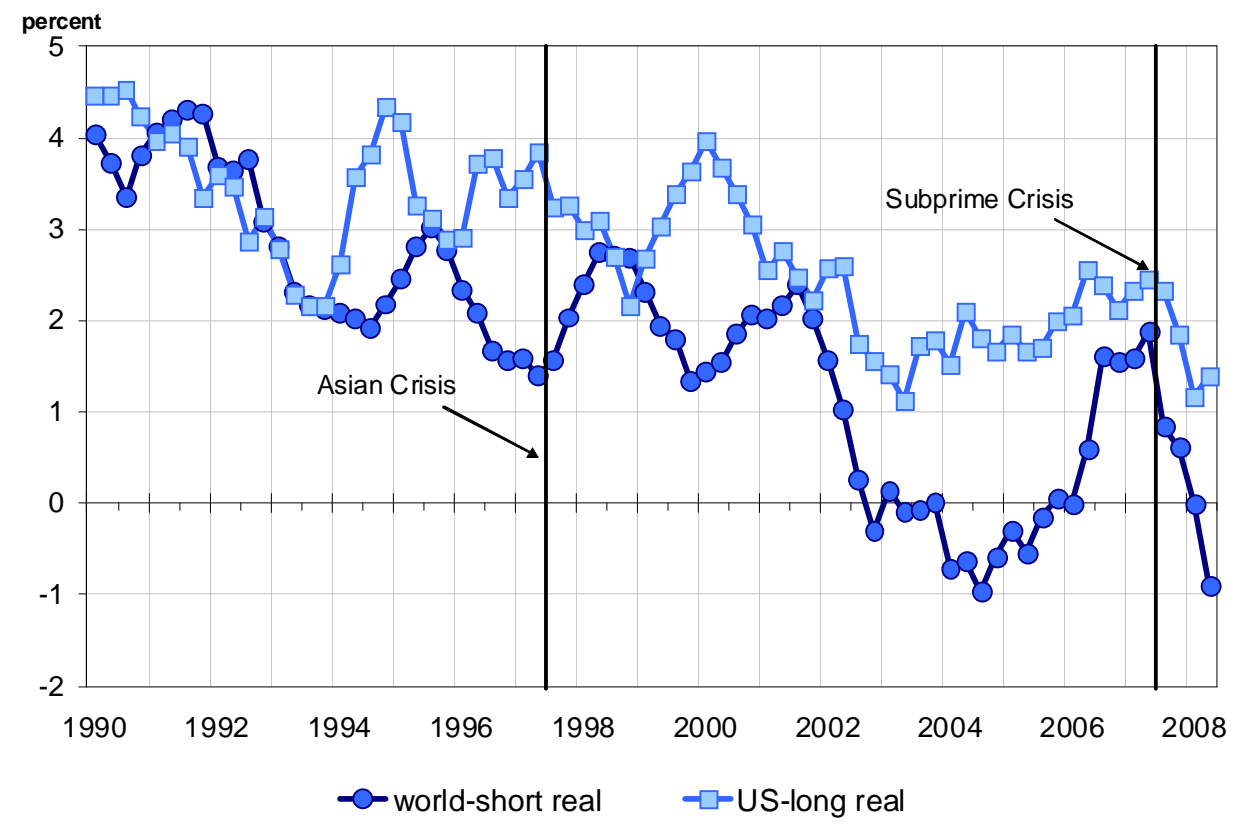

Figure 2: World and US Real Interest Rates, 1990:1-2008:2. Data Sources: IFS, WDI, OECD \& SPF, authors' calculations. The world short real rate is a GDP-weighted of the 4-quarter average ex-post 3-months Treasury Bill real rates for the G-7 countries.

recent years, reoriented capital flows from emerging markets toward the U.S.. In effect, EMs and commodity producers in need of sound and liquid financial instruments to store their newfound wealth, turned to the U.S. financial markets, perceived as uniquely positioned to provide these financial assets. ${ }^{2}$

As we explained then, a by-product of this reallocation of capital flows was a necessary decline in U.S. and world real interest rates and a boom in U.S. asset markets. Ex-ante real interest rates on 10-year U.S. government bonds fell below $2 \%$ in 2002 (figure 2) while the rate on a 30-year fixed rate conventional mortgage reached 5.23 percent in June 2003 (figure 3), with a 2.9 percent annual inflation. As foretold by then Governor Bernanke in his influential 'Savings Glut' speech (Bernanke (2005)), it is now apparent that this boom was located in no small part in a rise in U.S. housing markets and the related markets for structured credit instruments (figures 4 and 5). In the context of low real interest rates, U.S. households were encouraged to take on more housing risk than they could bear, risks that magically

\footnotetext{
${ }^{2}$ In recent years, a significant portion of the capital flows from EM countries to the U.S. took the form of official reserve accumulation. The composition of capital flows is not the focus of our analysis. Nonetheless, we observe that, especially in the case of China, most of these reserves are indirectly held by local investors through low-return sterilization bonds.
} 


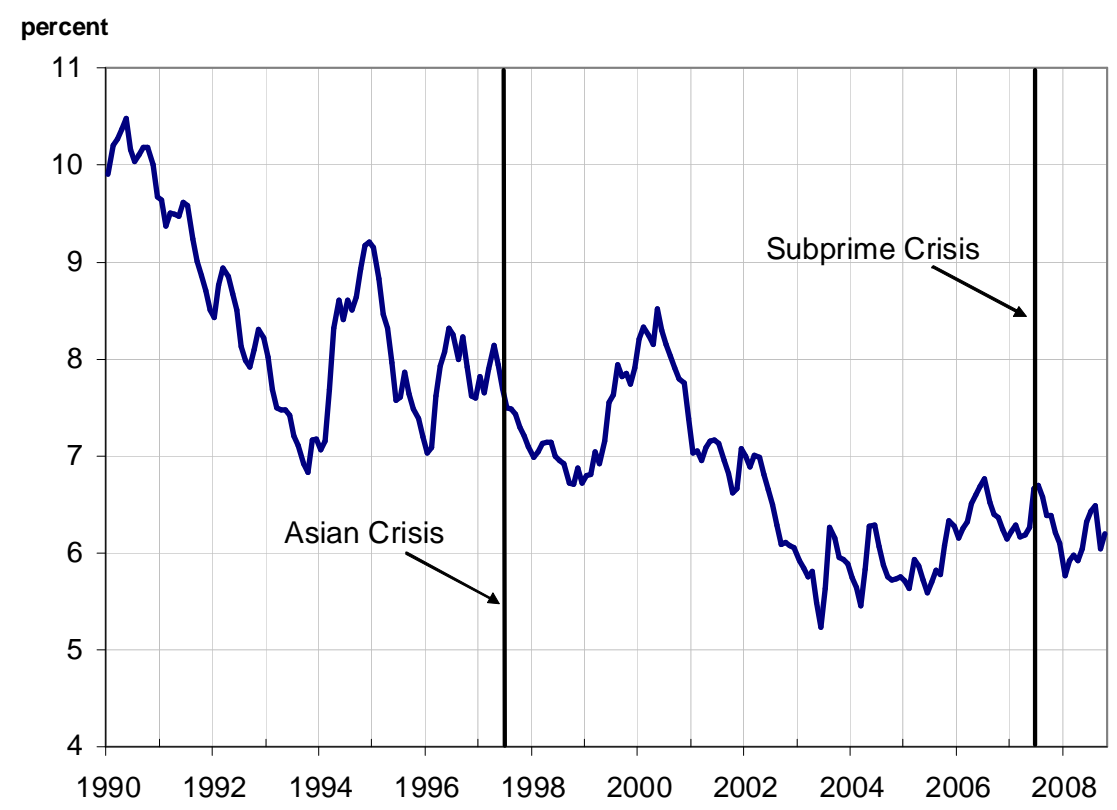

Figure 3: Contract Rate on 30-Year, Fixed-Rate Conventional Home Mortgage Commitments, 1990:1-2008:2. Data Source: Federal Reserve Bank series H15.

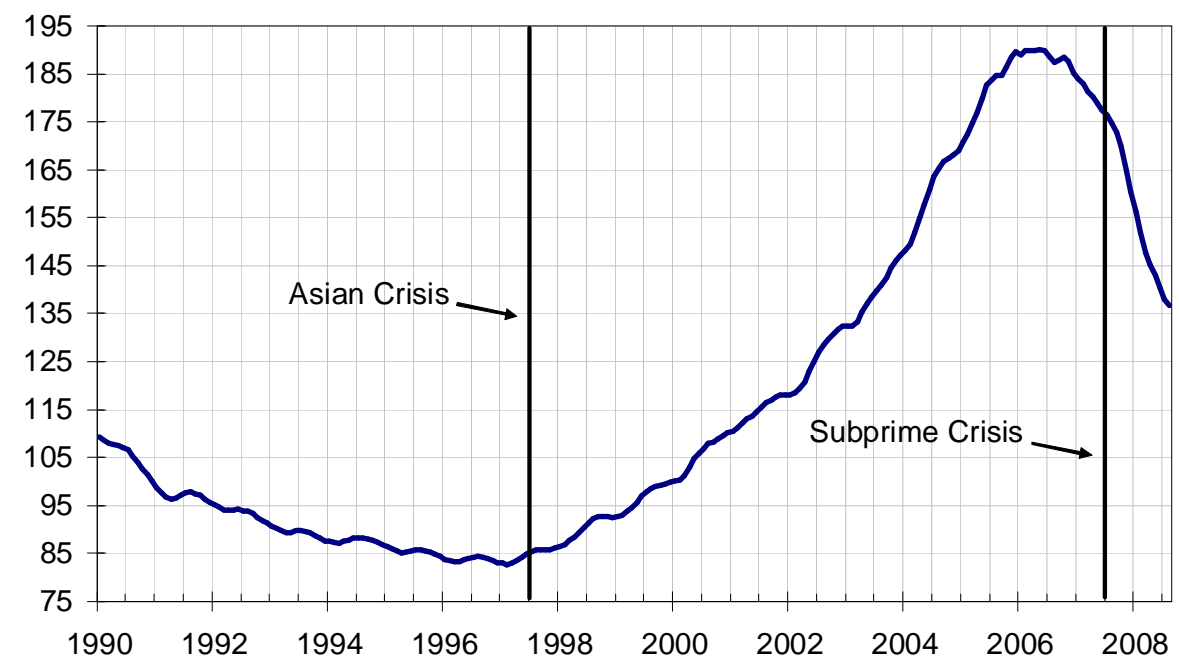

—S\&P/Case Shiller Composite-10 Price Index (CPI deflated)

Figure 4: S\&P Case Shiller Composite-10 Home Price Index (CPI-deflated) 1990M1-2008M8. 100 in January 2000. Data Source: Standard and Poors, IFS \& Authors' Calculations. 


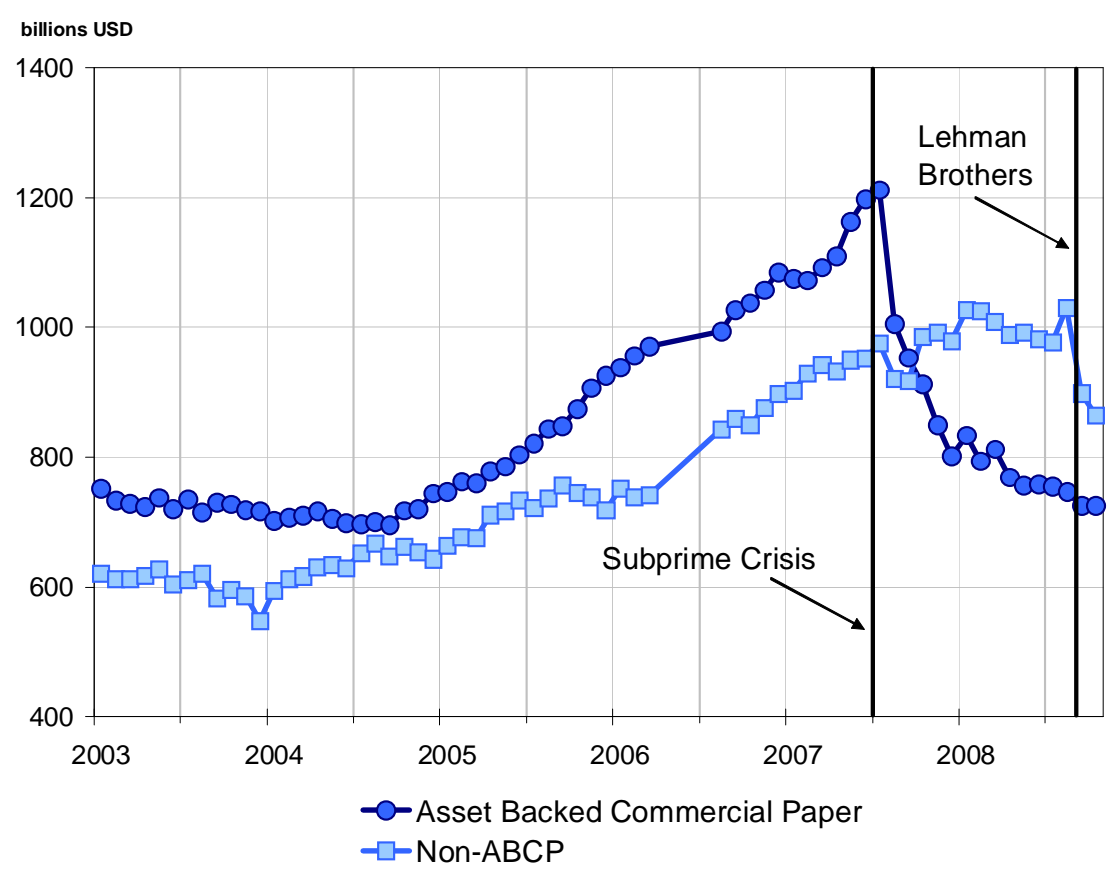

Figure 5: Commercial Paper, Amount Outstanding, billions USD. 2003M1-2008M10. Data Source: Federal Reserve Board.

disappeared from the mortgage-backed securities and other structured investment vehicles whose supply exploded over the same period (figure 5). The catastrophic and systemic failures of this originate-to-distribute model are now well-documented. ${ }^{3}$

By sometime in 2006, the appreciation in U.S. real estate prices came to a halt and the U.S. current account deficit began to turn around (see figures 1 and 4). Starting in earnest in June 2007, with the bailout of two Bear Stearns' funds that could not meet their margin calls, the world economy entered, with a certain fracas, into a period of significant global adjustment. Within weeks, funding dried up for entire segments of the U.S. and international banking sector, especially asset-backed commercial paper (see figure 5), leading to major convulsions of credit and money markets, including the dramatic collapse and rescue of several U.S. and European commercial and investment banking institutions. More than 12 months after the onset of the crisis, financial markets appear nowhere near stabilized. In fact, by the beginning of the summer of 2008, financial distress in major players began to accelerate, a process that started with the government rescue of the Government Sponsored Enterprises (GSE) Fanny Mae and Freddy Mac in July and culminated with the failure of

\footnotetext{
${ }^{3}$ See Brunnermeier (forthcoming 2008) and Greenlaw, Hatzius, Kashyap and Shin (2008) for detailed and recent accounts of the subprime crisis.
} 


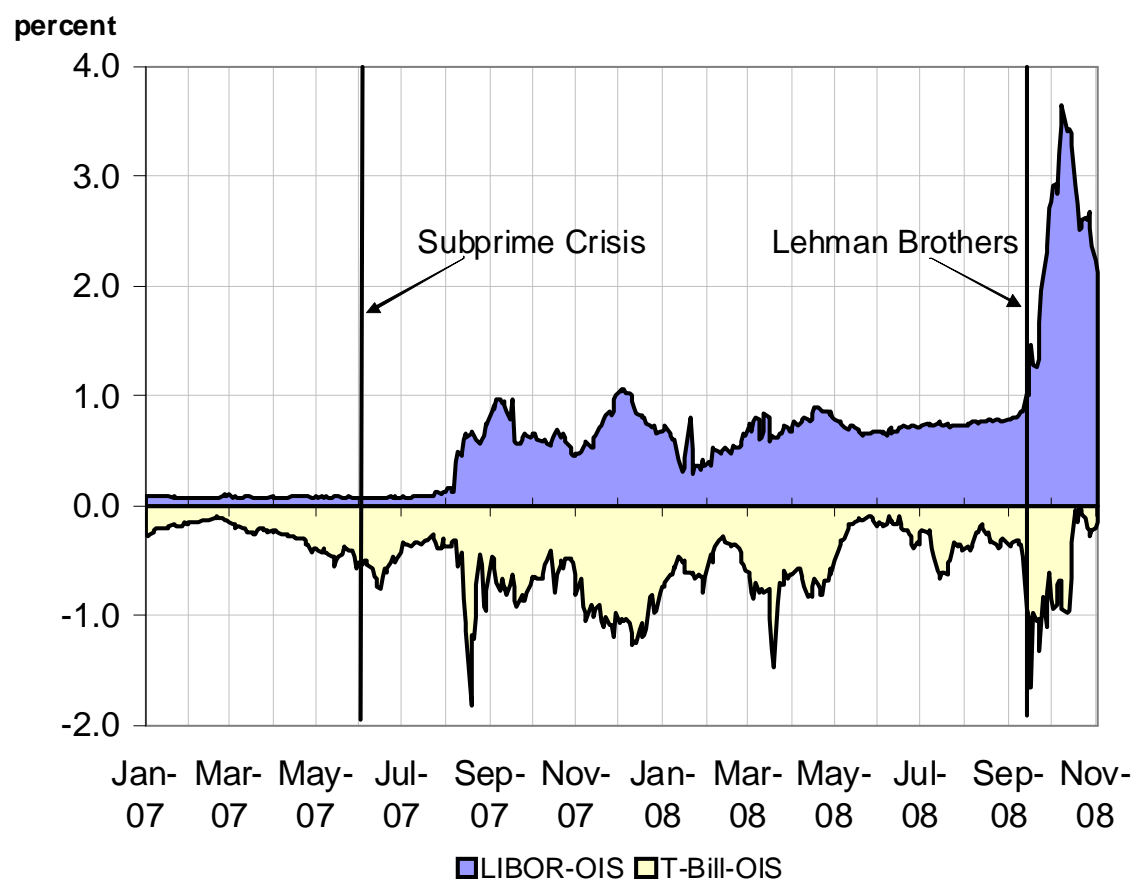

Figure 6: U.S. Treasury and LIBOR-OIS Spread. Jan-2007 to Oct-2008. Data Sources: MorganMarket; Authors' calculations.

Lehman Brothers on September 15. This was a watershed moment. Until then, the crisis had been severe, but largely contained within the financial sector of the economy. Following the collapse of the GSEs and of the entire U.S. broker-dealer industry, the seizing of wholesale money markets reached unprecedented proportions. Figure 6 decomposes the spread between 3-months LIBOR and 3-months Treasury yields (the TED spread) into a LIBOR-Overnight Index Swap (OIS) spread (top part) that measures interbank credit risk, and a Treasury-OIS spread (bottom part) that captures flight to liquidity. In the weeks following the collapse of Lehman Brothers, both components of the spread increased dramatically, with the TreasuryOIS spread reaching 165bp on September 17 and the LIBOR-OIS spread reaching 365bp on October 10. With credit markets on life support the crisis quickly spread to the rest of the economy.

Most likely, the strong U.S. capital inflows of the last few years contributed to the significant weakening of U.S. credit markets. The eventual recognition of their degraded performance was one of the triggers of the current crisis. However, this weakening is in itself part of the endogenous response of U.S. financial markets to world financial conditions. In effect, U.S. assets became stretched by trying to accommodate the world's excess demand 
for assets. Therein lies the structural problem. This chronic excess demand for assets derives from financial underdevelopment in emerging markets and most commodity producing economies, rather than from macroeconomic imbalances. Excess asset demand leaves an unmistakable signature in low real interest rates, which in turn provide a fertile ground for bubbles to emerge. Thus an alternative -perhaps metaphoric-interpretation of the sequence of events is that the bubble located in emerging markets during the 1990s migrated toward the U.S. housing and credit markets (and the NASDAQ before that) following the EM crisis and the coming on-line of capitalist China. ${ }^{4}$

With the U.S. financial crisis, that bubble collapsed as well. Initially, the excess asset demand that produced it did not. Emerging Markets and commodity producers were, more than ever, in search of investment opportunities. Witness the long list of sovereign wealth funds and the financial means at their disposal. According to Deutsche Bank (2007), Sovereign Wealth Funds managed $\$ 3$ trillion USD as of September 2007, and were expected to manage an additional $\$ 7$ trillion within the next ten years. ${ }^{5}$ Another bubble was likely to appear as the endogenous response of a world economy that tried to increase the global supply of financial assets. We argue that it did so quickly, in the form of a commodity bubble. Figure 7 reports the real price of a barrel of West Texas Intermediate (WTI) in 2008 U.S. dollars. Between June 2007 and June 2008, real crude prices increased by almost 100 percent. During the summer of 2008, however, as the financial crisis spread and economic growth started to decline, commodity prices suffered a dramatic collapse. Between July 2008 and October 2008, real crude prices declined by almost 53 percent, bringing them back to their level of June $2007 .^{6}$

Essentially, in the first phase of the crisis the combination of a tight commodity market and the decline in equilibrium real interest rates made it privately worthwhile to transform commodities into an asset (or even a new bubble). The mechanism is related (but not identical) to that in Hotelling (1931): Sufficiently low real interest rates make inventory

\footnotetext{
${ }^{4}$ See Caballero and Krishnamurthy (2006) for a model of bubbles and capital flows in emerging markets based on financial underdevelopment.

${ }^{5}$ These figures are being revised downward as a result of the brutal slowdown in world economic growth.

${ }^{6}$ This price pattern is quite general. It is apparent for energy commodities (coal, gasoline, heating oil), or biofuels such as corn. It is also present for most metals (aluminum, lead, copper, gold and silver) with the exception of zinc and nickel whose price peaked earlier in 2007. We find it also for most food prices (wheat, soybean, coffee, tea, cocoa, barley, rice, palm oil, groundnuts and rapeseed oil), less so for (sugar, cattle and hog). Our model provides a broad brush to understand the general evolution of commodity prices. Yet, individual commodities might also be affected by other factors - supply disruptions, weather, commodityspecific demand shocks. We also note that high energy prices generally push up food prices through higher production costs, and stronger competition for acreage from biofuels
} 


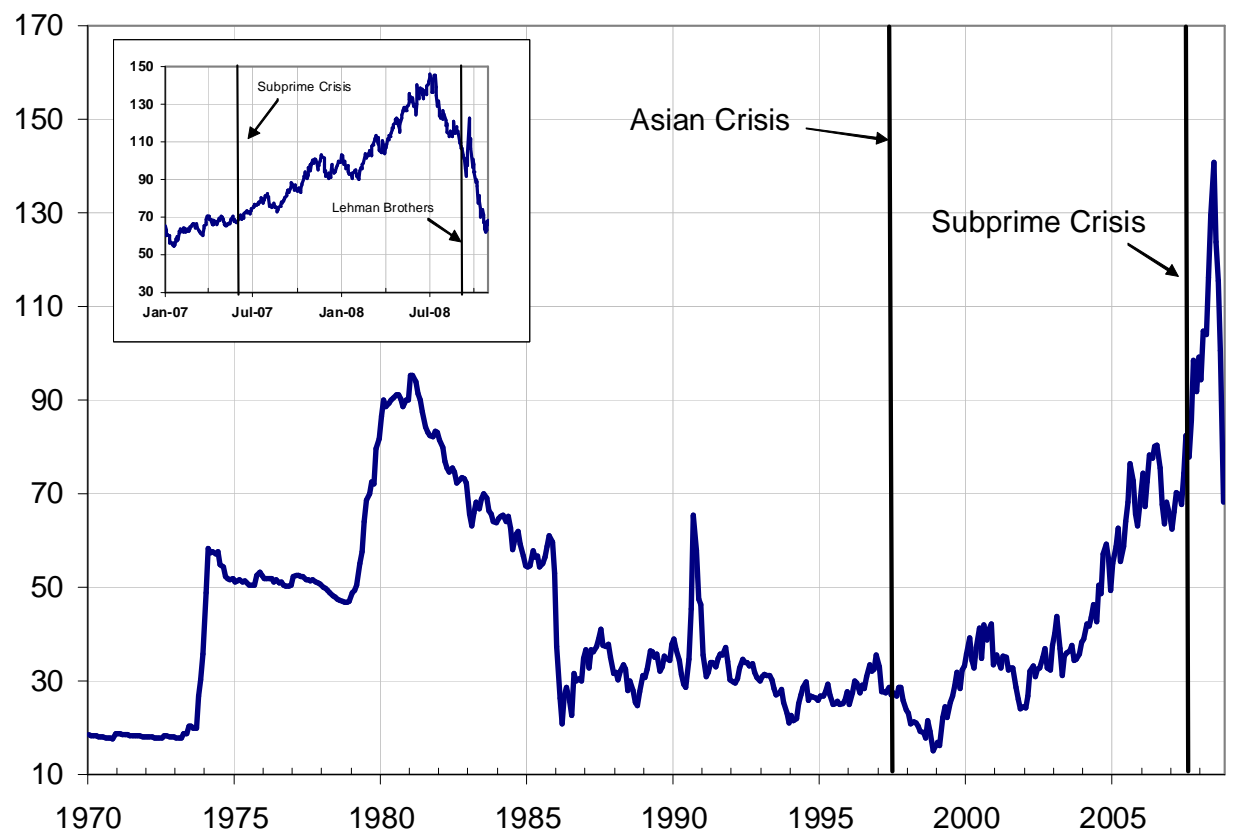

Figure 7: Real Price of West Texas Intermediate barrel of oil, 2008 dollars. Jan-1970 to Oct-2008. Data Sources: Global Financial Database \& IFS; Authors' calculations.

accumulation profitable and drive up the price of exhaustible resources. However, in the second phase the market-tightness precondition disappeared, which in turn destroyed the asset-accumulation incentive behind the feverish rise in commodity prices, triggering the collapse in these prices.

Figure 8 presents a scatter plot of crude oil prices against the S\&P500 index from 2004 to 2008. The graph clearly illustrates the different phases of the crisis. Prior to June 2007, the correlation between oil and U.S. stock prices was positive. During the first phase of the crisis, from July 2007 to June 2008, the correlation is strong and negative. Finally, since July 2008, the correlation again becomes strong and positive. The negative correlation during the first phase of the crisis is especially interesting from our point of view. Purely demand driven explanations of the surge in commodity prices would predict a positive correlation between assets and commodity prices. Later in this paper we provide instrumental variables evidence to support the claim that the negative correlation in this phase is not due to oil shocks but due to the financial mechanism we describe.

Let us now return to the implication of these developments for the global imbalances. According to Caballero et al. (2008), the sharp contraction in U.S. asset supply caused by 


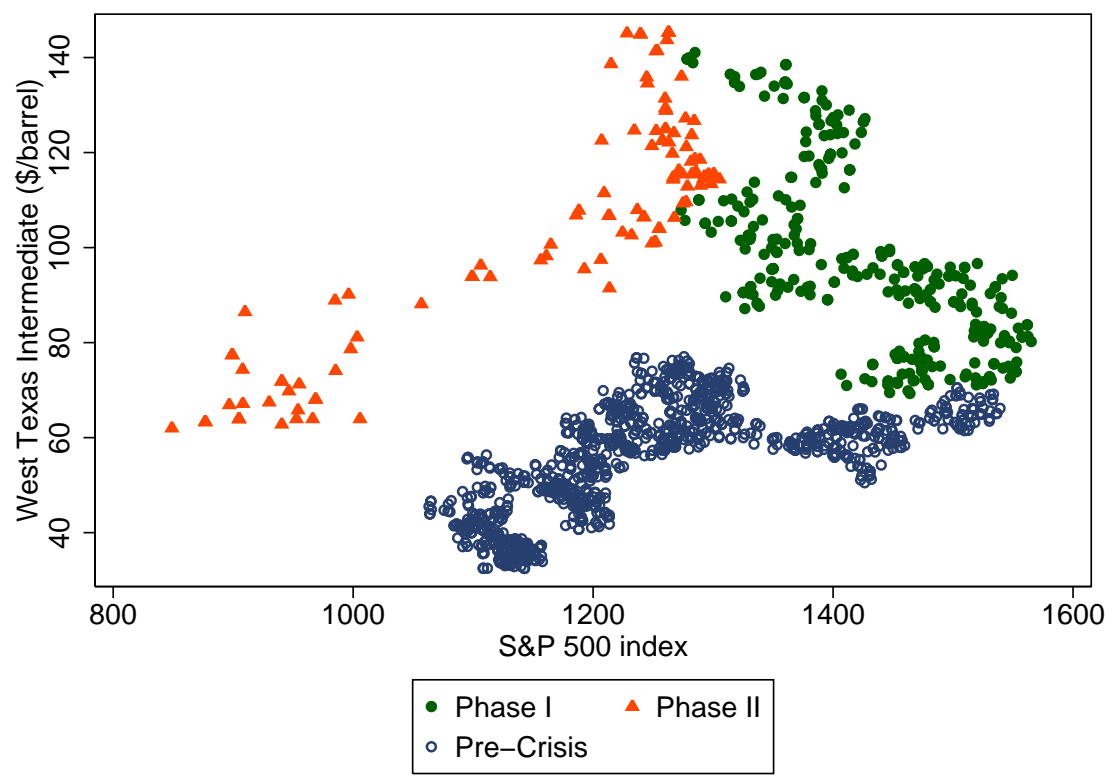

Figure 8: WTI prices (\$/barrel) and S\&P 500 index, Jan-2004 to Nov-2008. Phase I: July 1 2007 to June 30 2008; Phase II: July 12008 to November 8 2008. Data Sources: Global Financial Database; Authors' calculations.

the subprime crisis should lower equilibrium interest rates and trigger a rebalancing away from now 'toxic' U.S. assets. ${ }^{7}$ The resulting decline in U.S. wealth reduces domestic consumption, and improves the trade balance and the current account. This is in line with what we observed since June 2007: U.S. long real rates fell from 2.3 percent to 1.4 percent by June 2008 (Figure 2). The current account (trade) deficit improved from 5.6 (5.2) percent of GDP in June 2007 to 5.0 (5.0) percent in June 2008.

While qualitatively correct, the initial response of the trade balance and the current account was muted relative to what our basic view implies. That is, if the relative financial appeal of the U.S. is what is behind the initial imbalances, why didn't the subprime crisis did not lead to a sharper turn around in the U.S. current account? Again, we argue that the answer lies in the endogenous response of commodity prices. Because commodity inventories were initially very low, a by-product of the strong demand arising from the robust growth of emerging economies, the net asset creation from the commodity mechanism is initially small. In contrast, the strong impact of the price rise on the income of commodity-producing economies leads to a sharp rise in their demand for store of values, which further depresses

\footnotetext{
${ }^{7}$ The model predicts a simultaneous move towards 'safe' US assets. This flight-to-quality is an important feature of our analysis.
} 
real interest rates and stabilizes capital outflows to the U.S. in the short run. ${ }^{8}$

In the second phase of the crisis, external imbalances may or may not increase. Two offsetting forces are at play. On the one hand, the decline in economic growth reduces asset supply. This tends to depress interest rates and increase capital outflows to the US. Simultaneously, the collapse in commodity prices makes commodity producers poorer, hence reducing asset demand. For low levels of inventories, this second effect may dominate so that interest rates rise and external imbalances are reduced.

The rest of the paper provides a model and a quantitative assessment of the story and mechanisms we just described. The model is based on Caballero et al. (2008) with commodities. It has two regions, $U$ and $M$. We interpret $U$ as the U.S. and $M$ as the rest, with an emphasis on emerging market economies and commodity producers. The model features two goods: A non-storable good, $X$, produced by both countries and a storable commodity, $Z$, that is only produced by $M$. The supply of $X$ grows exogenously while the supply of $Z$ is constant. This is meant to capture the growing demand pressures on commodities that arise from robust world economic growth. We set-up the model so that a bubble develops initially in $U$. As discussed above, we interpret this bubble metaphorically as the extent to which asset markets in $U$ are stretched to provide financial assets to the rest of the world. With the bubble, the U.S. runs a larger current account deficit (the external imbalances) and world interest rates are low.

The original event in our model is the U.S. financial crisis: The bubble bursts at $t=0$, leaving savers scrambling for alternative stores of values. The resulting decline in real interest rates has two effects. First, it increases the value of 'good' $U$ assets. This translates into a flight-to-quality, from the bubble to the 'good' $U$ asset. Second, and more importantly, it triggers the commodity markets into action. As speculative hoarding takes place, the price of commodities jumps. Per se, this increase in commodity prices results in a significant wealth transfer from $U$ to $M$. But $M$ needs good stores of value. Thus a significant portion of that newfound wealth finds its way back into $U$. The resulting capital inflows further boost the value of the domestic asset and cushion the impact of the bubble's burst. Eventually, and gradually, the increase in asset supply due to commodity inventories pushes up interest rates, which forces rebalancing in $U$. To capture the second phase of the crisis, we assume that

\footnotetext{
${ }^{8}$ The reader may wonder why the rise in the price of oil is not simply a transfer of income from oil consumers to producers and hence has no impact on asset demand. The answer is in our choice of numeraire, which is the non-commodity good. This will be clearer once we describe the model but, as with all normalizations, it has no substantive implications.
} 
somewhere along this process, the financial crisis compromises global growth. The decline in global growth removes the asset market excess demand, which leads to a decumulation of inventories and a rapid collapse in commodity prices, alongside with asset prices.

Before turning to the details, it is worth clarifying two modeling subtleties that are important in interpreting our formal discussion. First, while the commodity side of our model shares some of Hotelling (1931)'s seminal insights, ours does not rely on Hotelling's key stock constraint (exhaustible resource). Instead, in our context there is a flow-extraction constraint which is insufficient to meet demand growth. This mismatch is the main factor behind the structural trend in commodity prices. In this context, the subprime collapse superimposes on the previous trend a speculative reason (in the precise sense of a rational bubble) for price increases; and the collapse in global growth in the second phase of the crisis damages the structural reason (the trend) supporting the bubble. Second, this speculative factor raises the effective opportunity cost of resource extraction for producers since there is now an asset-opportunity-cost, as in Hotelling's model, which reduces extraction incentives for commodity producers. The latter response means that, in equilibrium, there need not be any rise in measured inventories, and hence our allusion to inventories throughout this paper includes previously unextracted commodities.

Section 1 describes the basic mechanism connecting the financial crisis to commodity prices. Section 2 focuses on long-run global imbalances, while section 3 discusses shortrun imbalances and presents some back-of-the-envelope estimates of the effects we describe. Section 4 calibrates the model and explores its dynamic implications. Section 5 presents evidence supporting the speculative nature of the rise in oil prices following the subprime crisis, and of the recent drop in these prices. Section 6 concludes. Most formal derivations as well as explorations of some extensions of the model (such as the role of future markets and inventory trends) are relegated to appendices.

\section{Global Capital and Commodity Markets}

\subsection{The model for the world economy}

Time evolves continuously. Infinitesimal agents (traders) are born at a rate $\theta$ per unit of time and die at the same rate; population mass is constant and equal to one. Agents receive some endowment at birth, which, for simplicity, they save in its entirety until they die. Denote by 
$W_{t}$ the savings accumulated by households at date $t$. In every period, aggregate consumption $C_{t}$ is then a constant fraction $\theta$ of these accumulated savings: ${ }^{9}$

$$
C_{t}=\theta W_{t}
$$

Households consume a basket of two goods: an $X$-good (the numeraire) and a $Z$-good. Intratemporal preferences over these two goods are of the constant-elasticity-of-substitution (CES) type:

$$
C_{t}=\left[C_{X, t}^{(\sigma-1) / \sigma}+\alpha^{\frac{1}{\sigma}} C_{Z, t}^{(\sigma-1) / \sigma}\right]^{\sigma /(\sigma-1)} .
$$

$\sigma>0$ is the elasticity of substitution while $\alpha>0$ controls the equilibrium share of expenditures on the $Z$-good.

Given a relative price $p_{t}$ of the $Z$-good, households split their consumption between both goods as follows:

$$
C_{X, t}=\frac{\theta W_{t}}{1+\alpha p_{t}^{1-\sigma}} \text { and } C_{Z, t}=\frac{\alpha p_{t}^{-\sigma} \theta W_{t}}{1+\alpha p_{t}^{1-\sigma}}
$$

The $X$-good is a conventional non-storable good, while the $Z$-good is a storable commodity. Denote by $I_{t} \geq 0$ the outstanding inventories of the $Z$-good. Storing the commodity imposes an iceberg storage cost $d \geq 0$ per unit of time and good stored. Denote $r_{t}$ the instantaneous interest rate (in terms of the $X$-good). By arbitrage, $p_{t}$ must satisfy:

$$
\frac{\dot{p}_{t}}{p_{t}} \leq r_{t}+d
$$

with equality if $I_{t}>0$ or $\dot{I}_{t}>0$. This arbitrage equation is central to the analysis of storable commodities, such as Hotelling (1931). It states that the capital gains on commodities cannot exceed the interest rate, net of any convenience yield or carrying cost.

The endowment of the $X$-good, denoted $X_{t}$, grows at rate $g>0$ over time. By contrast, we assume that the endowment of the $Z$-good is constant through time: $Z_{t}=Z$, which allows us to capture the idea that demand pressures on commodities are growing over time. ${ }^{10}$

\footnotetext{
${ }^{9}$ As Caballero et al. (2008) show, this can be interpreted equivalently as log-preferences over consumption streams.

${ }^{10}$ Note that our model differs from Hotelling (1931)'s in that we replace his stock constraint with a flow constraint on commodity production. This has important implications later on since it allows us to separate more cleanly the asset-aspect of commodities from their goods-aspect. Moreover, in our framework, macroeconomic conditions determine whether one aspect or the other dominates in price-determination. See Jovanovic (2007) for a Hotelling based model of bubbles in exhaustible resources.
} 
The $Z$-good is assumed to be noncapitalizable unless it is transformed into inventories (below or above the ground). In contrast, a fraction $\delta$ of the $X$-good is capitalizable. We capture this feature as follows. At every point in time, there is a number $X_{t}$ of identical trees with an aggregate market value of $V_{t}$. Each tree yields 1 unit of $X$-good, a fraction $\delta$ of which is distributed to its current owners. Since the number of trees grows at rate $g$, the total value of new trees is $g V_{t}$ per unit of time. The fraction of the output that is not capitalized is distributed to newborns, as are the new trees. Hence, the total endowment received by newborns per unit of time is composed of $(1-\delta) X_{t}$ units of the $X$-good, $Z$ units of the $Z$-good and $g X_{t}$ new trees. The value of this endowment is $(1-\delta) X_{t}+p_{t} Z+g V_{t}$.

The return on existing trees is the dividend price ratio $\delta X_{t} / V_{t}$ plus the capital gain $\dot{V}_{t} / V_{t}-g$ which, in equilibrium, must be equal to the instantaneous interest rate in the economy, $r_{t}$ :

$$
r_{t} V_{t}=\delta X_{t}+\dot{V}_{t}-g V_{t} .
$$

In addition to the tree asset, some of our equilibria will exhibit rational bubbles, $B_{t}$, which must satisfy the arbitrage condition:

$$
\dot{B}_{t}=\left(r_{t}+\lambda\right) B_{t},
$$

where $\lambda>0$ is the hazard that the bubble bursts in the next instant. For simplicity we analyze the limit case as $\lambda$ goes to zero and $d>\lambda$. These assumptions allow us to approximate the solution with the perfect foresight case and to reduce the number of subcases we need to discuss.

Savings decrease with withdrawals (deaths), and increase with the endowment allocated to new generations and the return on accumulated savings:

$$
\dot{W}_{t}=-\theta W_{t}+(1-\delta) X_{t}+p_{t} Z+g V_{t}+r_{t} W_{t} .
$$

In equilibrium, savings must be equal to the value of all the assets in the economy:

$$
W_{t}=V_{t}+p_{t} I_{t}+B_{t} .
$$


Using (3) and imposing market clearing in the $X$-good market, we obtain:

$$
\frac{\theta W_{t}}{1+\alpha p_{t}^{1-\sigma}}=X_{t} \text { and } \frac{\alpha p_{t}^{-\sigma} \theta W_{t}}{1+\alpha p_{t}^{1-\sigma}}=Z-\dot{I}_{t}-d I_{t} .
$$

In equilibrium, replacing (9) back into (7), yields the equilibrium interest rate (for the case with inventories, i.e. $\left.\max \left\langle I_{t}, \dot{I}_{t}\right\rangle>0\right)$ :

$$
r_{t}=\theta \frac{\left(\delta+g \frac{B_{t}+p_{t} I_{t}}{X_{t}}\right)-\left(\frac{p_{t} Z}{X_{t}}-\alpha p_{t}^{1-\sigma}\right)}{1+\alpha \sigma p_{t}^{1-\sigma}}+\epsilon_{d} .
$$

where $\epsilon_{d}$ is an expression that plays no role in our main discussion. ${ }^{11}$

The interest rises as $\theta$ rises because a higher $\theta$ increases consumption and reduces asset demand. The two terms in parentheses in the numerator are central to our discussion below. The first of these terms represents asset supply: the interest rate rises with $\delta$ and with $B_{t}+p_{t} I_{t}$ because they increase asset supply. The second term represents the "petrodollar" effect and is present when inventories are being accumulated: When the price of commodities rises, the income of oil producers rises more than the effective income of oil-consumers falls. This net income effect lowers interest rates because it raises asset demand.

Later on we will see that for plausible parameter values, the asset demand effect dominates the asset supply effect in the short run, and so that an increase in the price of oil puts downward pressure on real interest rates. Since commodity prices also rise when interest rates fall (see (4)), the interaction between commodity prices and real interet rates gives rise to potentially large feedbacks.

\subsection{The $\sigma=1$ case}

Although in practice the short run elasticity of demand for the $Z$-good is significantly smaller than one, it is useful to start with the case $\sigma=1$ since it allows us to characterize explicitly the main mechanisms at work. We simplify things further by studying the case where $d$ converges to zero (while preserving the assumption $d>\lambda$ ).

Assume momentarily that the equilibrium has neither inventories nor bubbles. Replacing (9) back into (7) yields a reference interest rate, $r^{r e f}=\theta \delta /(1+\alpha)$. Henceforth we shall

\footnotetext{
${ }^{11} \epsilon_{d} \equiv-d(\sigma-1) \alpha p_{t}^{1-\sigma} /\left(1+\alpha \sigma p_{t}^{1-\sigma}\right)$.
} 
assume that financial assets are sufficiently scarce $(\delta$ low $)$ for the economy to be dynamically inefficient $\left(r^{r e f}<g\right)$ :

Assumption 1 Dynamically Inefficient Economy: $\delta<g(1+\alpha) / \theta$

Bubbleless equilibrium. Suppose for now that there are no bubbles, then the equilibrium must have inventories. To see this, note that if there are no inventories $r=r^{r e f}<g$. But in this case equation (9) requires $p_{t}=\alpha X_{t} / Z$, so the price of commodities grows at a rate $g$ which exceeds the equilibrium interest rate. Thus, there is a clear incentive to accumulate inventories, which is a contradiction of the no-inventories premise.

From (4) and (9), the dynamics of the economy can be summarized in a simple sytem with variables $I_{t}$ and $q_{t} \equiv p_{t} / X_{t}$ :

$$
\left\{\begin{array}{l}
\dot{I}_{t}=Z-\alpha q_{t}^{-1} \\
\dot{q}_{t}=\left(r_{t}-g\right) q_{t}
\end{array},\right.
$$

where $r_{t}$ is given by:

$$
r_{t}=\theta \frac{\delta+\alpha-q_{t}\left(Z-g I_{t}\right)}{1+\alpha} .
$$

Asymptotically, the level of inventories stabilizes at a strictly positive level which is proportional to the degree of dynamic inefficiency in the economy:

$$
\lim _{t \rightarrow \infty} I_{t}=\bar{I}=\frac{1+\alpha}{\alpha \theta g}\left(g-r^{r e f}\right) Z>0 .
$$

The price $p_{t}$ of the $Z$-good grows at rate $g$ and the interest rates $r_{t}$ converges to the growth rate $g$ of the $X$-good.

Figure 9 reports the phase diagram associated with (11). The dynamic system exhibits the saddle-path property. ${ }^{12}$ This saddle-path is downward sloping: when inventories are low $\left(I_{t}<\bar{I}\right)$, the price of commodities is high $\left(q_{t}>\bar{q} \equiv \alpha / Z\right)$ and decreasing $\left(r_{t}<g\right)$. Conversely, when inventories are abundant $\left(I_{t}>\bar{I}\right)$, the price of commodities is low $\left(q_{t}<\bar{q}\right)$ and increasing $\left(r_{t}>g\right)$.

A key element of our model lies in the slope of this saddle-path. To understand why

\footnotetext{
${ }^{12}$ Figure 9 is drawn for the case where $\theta \delta /(1+\alpha)<g<\theta(\delta+\alpha) /(1+\alpha)$, where the first inequality is a consequence of assumption 1. The case where $g>\theta(\delta+\alpha) /(1+\alpha)$ is similar and features also a downward sloping saddle-path, but the $\dot{q}=0$ schedule is downward sloping.
} 


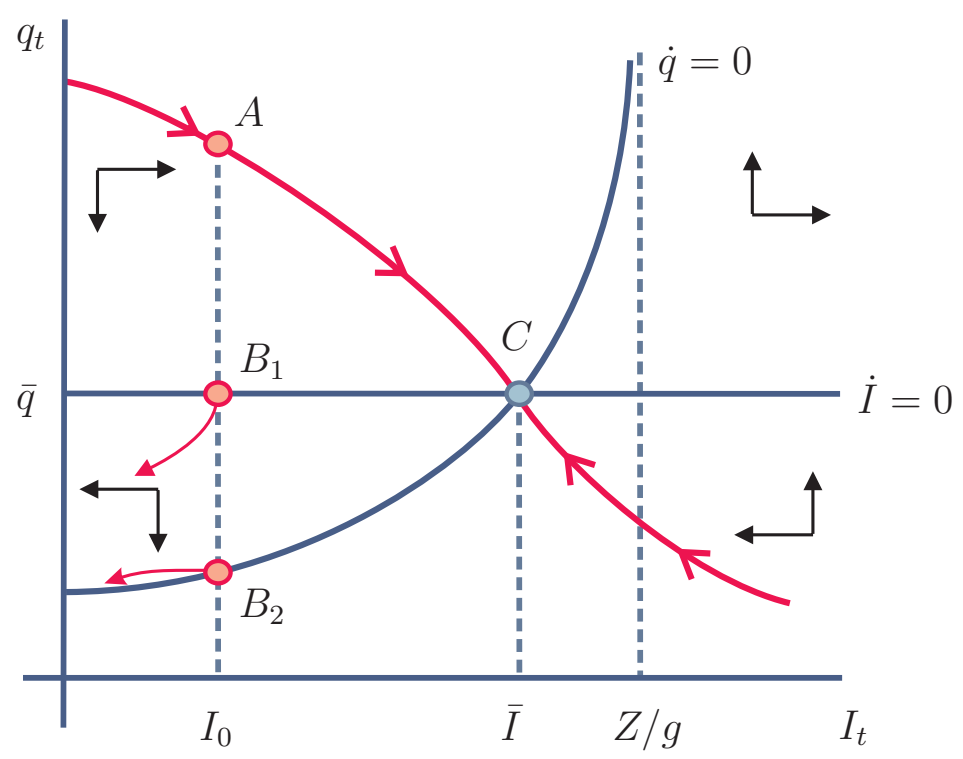

Figure 9: The Model with Inventories when $\sigma=1$.

it is downward sloping, consider an initial inventory position $I_{0}<\bar{I}$ and suppose that the price is such that the commodity market is initially in equilibrium at that inventory level $\left(\dot{I}_{0}=0\right.$,or $\left.q_{0}=\bar{q}\right)$. This is point $B_{1}$ on figure 9 . It is immediate that the interest rate $r_{0}$ that clears the asset markets at point $B_{1}$ must be below the growth rate $g$. The economic intuition is that at $q=\bar{q}$, too few assets are created through inventories (whose value is $\left.\bar{q} I_{0}\right)$. Equilibrium on global asset markets then requires a low interest rate. But when $r_{0}<g$, the (normalized) price of commodities declines over time, which increases demand for commodities and reduces inventories $\left(\dot{I}_{0}<0\right)$. Instead, the equilibrium requires that the price of commodities is initially sufficiently high to depress the demand for commodities, and allow inventory accumulation $\left(\dot{I}_{0}>0\right)$. Equivalently, the price of commodities needs to rise sufficiently to depress equilibrium interest rates and make inventory accumulation profitable. This is represented by point $A$ in the figure. This high initial price depresses interest rates below $r_{0}$. Over time, since $r_{t}<g$, (normalized) commodity prices decrease, which increases demand for commodities and slows down inventory accumulation. The steady state is reached at point $C$.

The price of commodities performs a dual role in the model with inventories: it influences the demand for the $Z$-good on the spot market; and it influences the global supply of assets in the economy $\left(V_{t}+p_{t} I_{t}\right)$. As in traditional models of portfolio balance, it is the tension 
between these two functions that generates interesting dynamics. ${ }^{13}$

Bubbles. Now let us turn to the opposite extreme, where bubbles exist and do not vanish asymptotically relative the size of the economy. In the limit, since we assumed $d>\lambda$, there are no inventories. Without inventories, the $Z$-good is for consumption only, and its price grows at rate $g$. The interest rate $r_{t}$ converges to $g$ and the bubble converges to:

$$
B_{t} \underset{t \rightarrow \infty}{\sim} \frac{1+\alpha}{\theta g}\left(g-r^{r e f}\right) X_{t}
$$

The size of the asymptotic bubble in (14) is the same as the size of the asymptotic equilibrium inventories $p I$ in the bubbleless equilibrium (13). In both cases, the endogenous increase in asset supply is just sufficient to increase the equilibrium interest rate to $g$.

The No-Inventory Economy (a benchmark). In our model, the price of the $Z$-good is both a relative price, and, when inventories are non-zero, an asset price. In order to illustrate the importance of this dual role, we provide a benchmark-economy where the inventory-channel is turned off. That is, we assume that storage costs are prohibitive (i.e., $d$ is very large) so the $Z$-good cannot be stored.

This benchmark economy has two long run steady-states: a bubbly one and a bubbleless one. The bubbly steady-state is exactly as above with the same equilibrium prices and quantities. However, the bubbleless equilibrium is different since inventories cannot be accumulated. In the bubbleless equilibrium, market clearing for the $Z$-good implies that $p_{t}$ grows at rate $g$. Equilibrium in asset markets implies that the interest rate $r_{t}$ is equal to $r^{r e f}<g$.

Note that Assumption 1 implies that the interest rate $r^{r e f}$ in the bubbleless equilibrium of the no-inventory economy is smaller than the interest rate $g$ of the bubbleless equilibrium of the economy with inventories. The reason for this difference is that total asset supply is smaller in the economy without inventories. Note also that $p_{t}$ is the same in the bubbly equilibrium and in the bubbleless equilibrium without inventories. That is, the price is entirely determined by the relative endowments of the $X$-good and the $Z$-good and is completely decoupled from the asset market.

\footnotetext{
${ }^{13}$ See Kouri (1982) and more recently Blanchard, Giavazzi and Sa (2005) for examples of the portfolio balance models.
} 


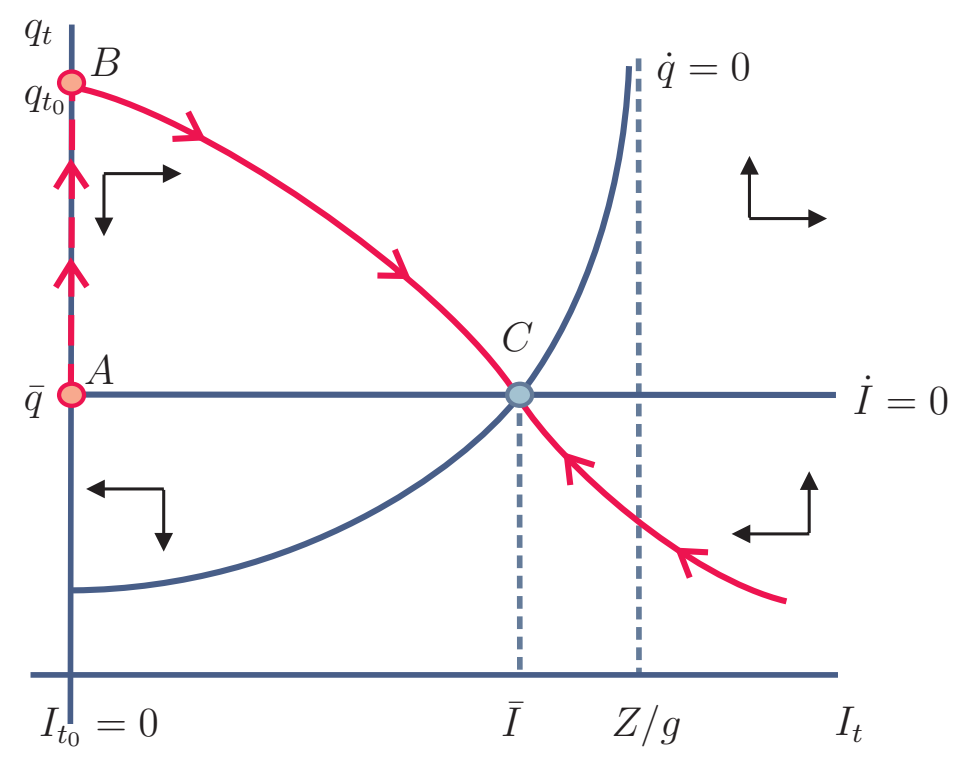

Figure 10: A 'Subprime Crisis' at $t=t_{0}$ when $\sigma=1$.

\subsection{The Financial Crash and Commodity Boom (Phase I)}

Suppose now that a 'subprime' shock takes place. This can be interpreted as the realization that financial instruments are less sound than they were once perceived to be. It could result from, inter alia, the realization that corporate governance is less benign than once thought (excessive risk-taking and poor risk management by investment banks, or the realization that securitization and certification by rating agencies involve important agency problems); a significant loss of informed and intermediation capital (deleveraging of commercial and investment banks hit by losses) and so on. All of these factors -and more- have been mentioned in the events surrounding the recent subprime crisis. ${ }^{14}$ We assume that this shock is completely unanticipated, but this is not crucial to our analysis as long as there is some degree of market incompleteness, preventing agents from fully hedging away.

In the model we capture this shock with a crash in the bubble $B$ at date $t_{0}$. The dynamics that follow are described by those in the bubbleless system and are illustrated in Figure 10. Right before the shock, the economy is at point $A$, with $q_{t_{0}}=\bar{q}$ and no inventories $\left(I_{t_{0}}=0\right)$. When the crisis erupts, the price of commodities jumps to point $B$, on the saddle-path. With decreased demand in the spot market, the economy immediately begins to build inventories (which could be kept under the ground). The price of commodities remains high until the economy converges to the new steady state (point $C$ ).

\footnotetext{
${ }^{14}$ See Greenlaw et al. (2008) and Brunnermeier (forthcoming 2008).
} 
The collapse of the bubble reduces asset supply and leads to a drop in the interest rate. Lower interest rates make more attractive the strategy of storing the $Z$-good to sell it in the future, which validates the build-up in inventories. Higher commodity prices along the transition are required to lower demand and restore equilibrium in the $Z$-good market. The commodity price jumps at $t=t_{0}$, and asymptotes from above to the same path as in the pre-crash economy.

The interest rates initially drops by:

$$
r_{t_{0}^{+}}-r_{t_{0}^{-}}=-g \frac{B_{t_{0}^{-}}}{W_{t_{0}^{-}}}-\frac{\theta \alpha}{1+\alpha}\left(\frac{p_{t_{0}^{+}}}{p_{t_{0}^{-}}}-1\right)<0
$$

and then converges smoothly back to the asymptotic level $g$. There are two terms on the right hand side of (15). The first "bubble-burst" term $-g B_{t_{0}^{-}} / W_{t_{0}^{-}}$is directly due to the collapse of the bubble. The second "commodity-price-jump" term follows from the increase in the price of the $Z$-good, which raises the rate of wealth accumulation. Since inventories are only gradually accumulated, an additional gap opens between asset supply and asset demand, which requires a further decline in interest rates.

In the benchmark no-inventory economy, the normalized price of commodities stays constant and equal to $\bar{q}$, so the economy remains indefinitely at point $A$ in figure 10 . Since the price of commodities does not jump, the second term in equation (15) would equal 0, and the interest rate drop would be entirely given by the bubble-burst term. ${ }^{15}$

Note that there is a strong flight-to-quality feature in the model since both the value of accumulated savings and the total value of assets are continuous at $t=t_{0}$ :

$$
W_{t_{0}^{-}}=\left(V_{t_{0}^{-}}+B_{t_{0}^{-}}\right)=W_{t_{0}^{+}}=V_{t_{0}^{+}}=\frac{1+\alpha}{\theta} X_{t_{0}}
$$

This means that the decline in interest rates raises the value of the trees (the 'good' asset) enough to fully offset the loss in value due to the crash in the bubble. Later on we will show that when $\sigma<1$, the decline in interest rate is more pronounced than in the $\sigma=1$ case, which further raises the value of the remaining good assets. ${ }^{16}$

\footnotetext{
${ }^{15}$ We know from the previous analysis that the interest rate would drop to $r^{r e f}=\delta \theta /(1+\alpha)$.

${ }^{16}$ Note that if we were to use a true CPI (rather than the price of good $X$ ) to deflate quantities, then wealth would always drop in real terms after a crash. This alternative numeraire formulation, which we develop in Appendix A.4, modifies the "language" but none of our substantive conclusions.
} 


\subsection{The Growth Slowdown (Phase II)}

Eventually, the financial crisis starts to hurt global growth prospects. We capture this turn of events by assuming that at $t=t_{1}$, global growth slows down unexpectedly and permanently from $g$ to $\hat{g}<g$. In the long run, the slowdown lowers the level of inventories $\bar{I}$. In fact, from (13) we see that if the growth slowdown is sufficiently severe as to reverse assumption 1 , the commodity bubble ultimately crashes and $\bar{I}=0$. We formalize this with the following assumption.

Assumption 2 Severe Growth Slowdown: $\hat{g}<\delta \theta /(1+\alpha)$

Under assumption 2, inventories are not sustainable in the long run. The dynamics that follow the growth slowdown are illustrated in Figure 11. At time $t_{1}$, the economy is at point $D$, with inventory levels $I_{t_{1}}$ and a commodity price $q_{t_{1}}$. Following the shock, the price of commodities needs to collapse, so as to pick up the slack from the decreased rate of inventory accumulation. Equivalently, the collapse in commodity prices from $D$ to $E$ pushes equilibrium interest rates to $r_{t}>\hat{g}$, making inventory accumulation less profitable. ${ }^{17}$ Over time, inventories converge to $\bar{I}=0$, while commodity prices increase back to $\bar{q}$ (point $A$ ), and the interest rate converges to $r^{\text {ref }}$.

By constrast, in the no-inventory economy, the commodity price and the interest rate would not be impacted at $t=t_{1}$. The economy would remain indefinitely at point $A$ in figure 11 .

\section{Global Imbalances in the Long Run}

Let us now study global equilibrium in a world with two large regions, $i=\{U, M\}$. We interpret region $U$ as the US, with initially good but perhaps fragile financial conditions,

\footnotetext{
${ }^{17}$ Note that while $r_{t_{1}^{+}}>\hat{g}$, the interest rate can increase or decrease when the growth shock hits, depending on the level of inventories $I_{t_{1}}$. This is because a decrease in commodity prices reduces both asset supply (the value of inventories decreases) and asset demand (the value of the flow of $Z$-goods decreases). When $I_{t_{1}}$ is small, the asset supply shifts less than the asset demand curve, requiring an increase in the interest rate to clear the asset market. We can compute the increase in interest rates,

$$
r_{t_{1}^{+}}-r_{t_{1}^{-}}=\frac{\theta}{1+\alpha} \frac{Z}{X_{t_{1}}}\left(p_{t_{1}^{-}}-p_{t_{1}^{+}}\right)+\frac{\theta}{1+\alpha} \frac{Z}{X_{t_{1}}}\left(p_{t_{1}^{+}} \hat{g}-p_{t_{1}^{-}} g\right) I_{t_{1}}
$$

where the second term on the right hand side is negligible if $I_{t_{1}}$ is small. Note that despite this potential increase at impact, the interest rate eventually converges to a lower level since $r^{\text {ref }}<g$ under assumption 1.
} 


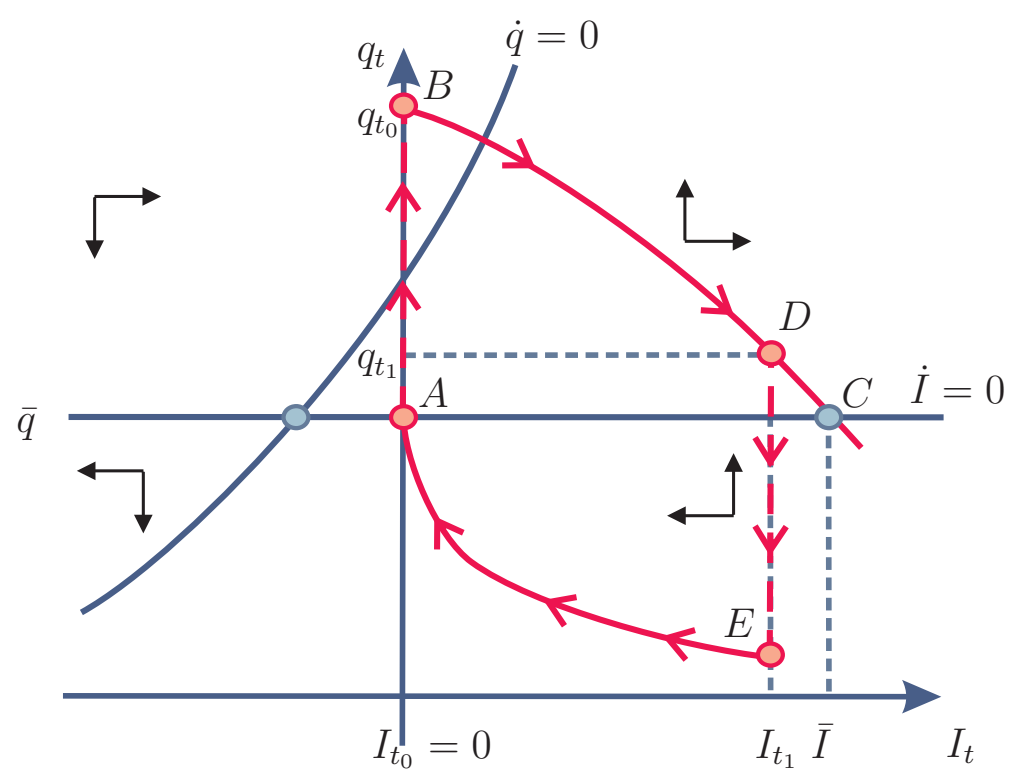

Figure 11: A Growth Slowdown at $t=t_{1}$ when $\sigma=1$.

and region $M$ as the set of emerging and commodity producing economies that offset U.S. external imbalances.

Each of the regions is described by the same setup as the world economy, with an instantaneous return from hoarding a unit of either tree, $r_{t}$, which is common across both regions and satisfies:

$$
r_{t} V_{t}^{i}=\delta X_{t}^{i}+\dot{V}_{t}^{i}-g V_{t}^{i}
$$

where $V_{t}^{i}$ is the value of country $i$ 's tree at time $t$. We assume initially that both regions have common parameters $g, \delta$ and $\theta$, but that the initial bubble is concentrated in the $U$ region. The latter captures the idea that the $U$ region has more attractive assets than the $M$ region. Moreover, we assume that the $Z$-good is produced only in the $M$ economy and that the potential inventories are held in this region (perhaps under the ground, see later discussion). These two features are all that differentiates the two regions, aside from scale.

Let $W_{t}^{i}$ denote the savings accumulated by agents in country $i$ at date $t$. By analogy with (7):

$$
\dot{W}_{t}^{i}=-\theta W_{t}^{i}+(1-\delta) X_{t}^{i}+g V_{t}^{i}+r_{t} W_{t}^{i}+1_{\{i=M\}} p_{t} Z_{t}
$$

where $1_{\{i=M\}}$ is an indicator for country $M$. Adding (16) and (17) for $U$ and $M$, the world economy is exactly the one described in Section 1 with:

$$
W_{t}=W_{t}^{U}+W_{t}^{M} ; \quad V_{t}=V_{t}^{U}+V_{t}^{M} ; \quad X_{t}=X_{t}^{U}+X_{t}^{M} ;
$$




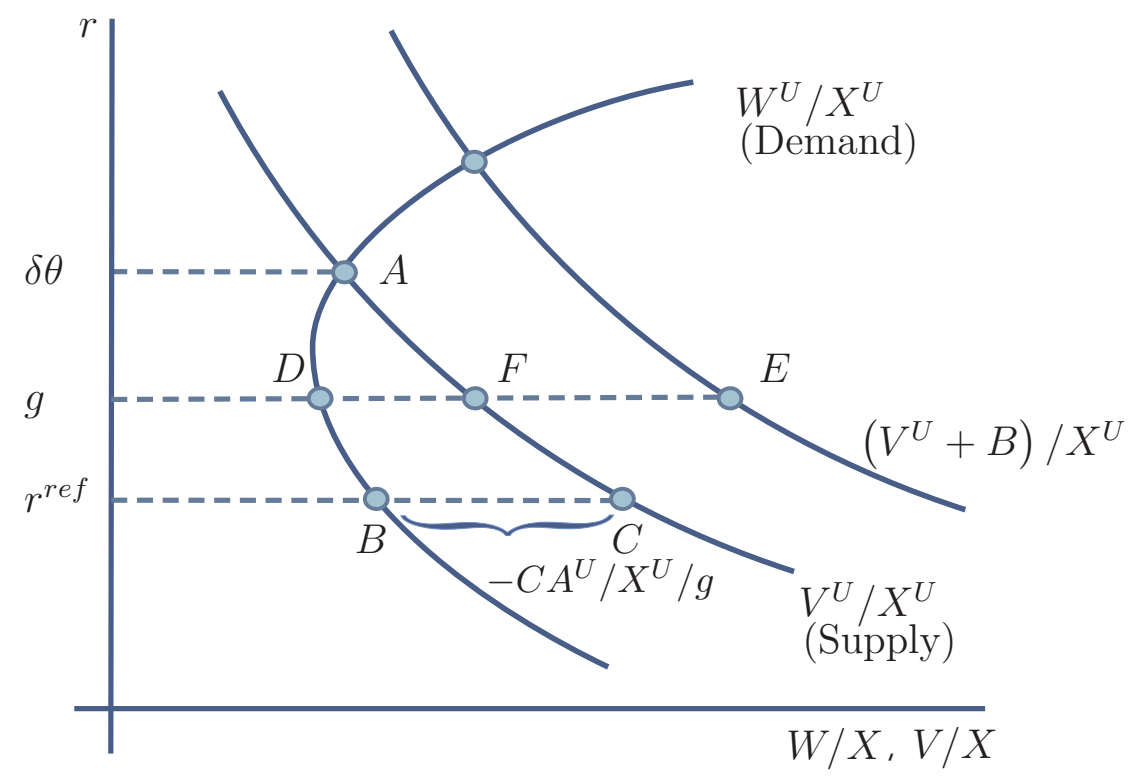

Figure 12: The Metzler Diagram when $\sigma=1$.

The current account $C A_{t}^{U}$ of country $U$ represents the net accumulation of assets by country $U$ and is given by

$$
C A_{t}^{U}=\dot{W}_{t}^{U}-\dot{V}_{t}^{U}-\dot{B}_{t}^{U} .
$$

Let us start from the steady-state with bubbles and $\sigma=1$ described in Section 1.2. Figure 12 represents graphically the external equilibrium in $U$ in a 'Metzler-diagram' (Metzler (1960)). The curve labeled $V^{U} / X^{U}$ represents the long run value of the $U$-tree, relative to output. It is equal to $\delta / r$ and decreases with the interest rate $r$. The curve labeled $W^{U} / X^{U}$ represents the long run value of the savings to output ratio, as a function of the equilibrium interest rate. It is equal to $(1-\delta+g \delta / r) /(\theta+g-r)$. It decreases, then increases with $r{ }^{18}$

Without bubbles or inventories, long run financial autarky is achieved at point $A$ with $r=\delta \theta$. Under financial integration, but still without bubbles or inventories, the interest rate is lower, at $r^{r e f}=\delta \theta /(1+\alpha)$. The reason for the lower equilibrium interest rate is that a larger fraction of global output is not capitalized when there are commodities. The lower interest rate allows $U$ to supply more assets to $M$ and to run a current account deficit that is proportional to the distance between points $B$ and $C$ on figure 12 .

\footnotetext{
${ }^{18}$ While the asset demand schedule $W^{U} / X^{U}$ can be downward sloping, the gap between $W^{U} / X^{U}$ and $V^{U} / X^{U}$, equal to $(1-\delta \theta / r) /(\theta+g-r)$, is always increasing with the interest rate. The downward sloping part of the $W^{U} / X^{U}$ curve comes from the impact of interest rates on asset demand through the new trees $g V^{U}$. When $g<\delta \theta$, the $W^{U} / X^{U}$ curve has the shape shown in figure 12 . When $g>\delta \theta$, the asset and demand curves cross on the downward sloping part of the asset demand curve $W^{U} / X^{U}$.
} 
In the presence of the bubble, the supply of assets increase from $V^{U} / X^{U}=\delta / g$ to

$$
\frac{V^{U}+B}{X^{U}}=\frac{\delta}{g}+\left(\frac{1+\alpha}{\theta}-\frac{\delta}{g}\right) \frac{X_{t_{0}}}{X_{t_{0}}^{U}}
$$

so as to eliminate the dynamic inefficiency of Assumption 1. The increase is such that the world equilibrium interest rate increases from $r^{r e f}$ to $g$. The current account deficit in the bubble equilibrium (proportional to the distance between points $D$ and $E$ ) is always larger than in the no-bubble \& no inventories case (the distance between points $B$ and $C$ ). ${ }^{19}$ The reason for this larger current account deficit is that a disproportionate share of $M$ 's income is non-capitalizable (because their commodity income, $p Z$, is noncapitalizable unless it is transformed into inventories), while $U$ produces a disproportionate share of the global assets.

\subsection{Long-Run Imbalances with no Growth Slowdown}

As before, the subprime shock takes place at $t=t_{0}$. In the long run, the presence of commodities leads to a larger global rebalancing in response to a subprime shock in the U.S. (the $U$-region). Let's consider first what happens if there is no growth slowdown. In this case, since the asymptotic interest rate in the absence of bubbles is still $r=g$, the asymptotic current account deficit of the $U$ region following the collapse of the bubble is smaller by exactly the size of the bubble:

$$
\frac{C A_{t}^{U}}{X_{t}^{U}} \underset{t \rightarrow \infty}{\sim} g\left[\frac{1}{\theta}-\frac{\delta}{g}\right]
$$

This asymptotic current account will be in deficit if the degree of dynamic inefficiency in the global economy is not too severe $(\delta \theta>g)$, as is assumed in Figure 12. Otherwise, the buildup in inventories is significant, which increases the supply of assets in the $M$ region and reduces its need to buy foreign assets for store of value.

This build-up of inventories implies that endogenous commodity prices lead to more rebalancing in the long-run. The reason is that inventories contribute to increasing asset

\footnotetext{
${ }^{19}$ Indeed, the increase in the current account deficit in the presence of the bubble can be computed as

$$
C A^{U} \text { no-bubble }-C A^{U}=\frac{g-r^{r e f}}{\theta /(1+\alpha)}\left[\frac{\alpha g}{(1+\alpha)\left(\theta+g-r^{r e f}\right)}+\frac{X}{X^{U}}-1\right]
$$
}

which is always positive under Assumption 1. 


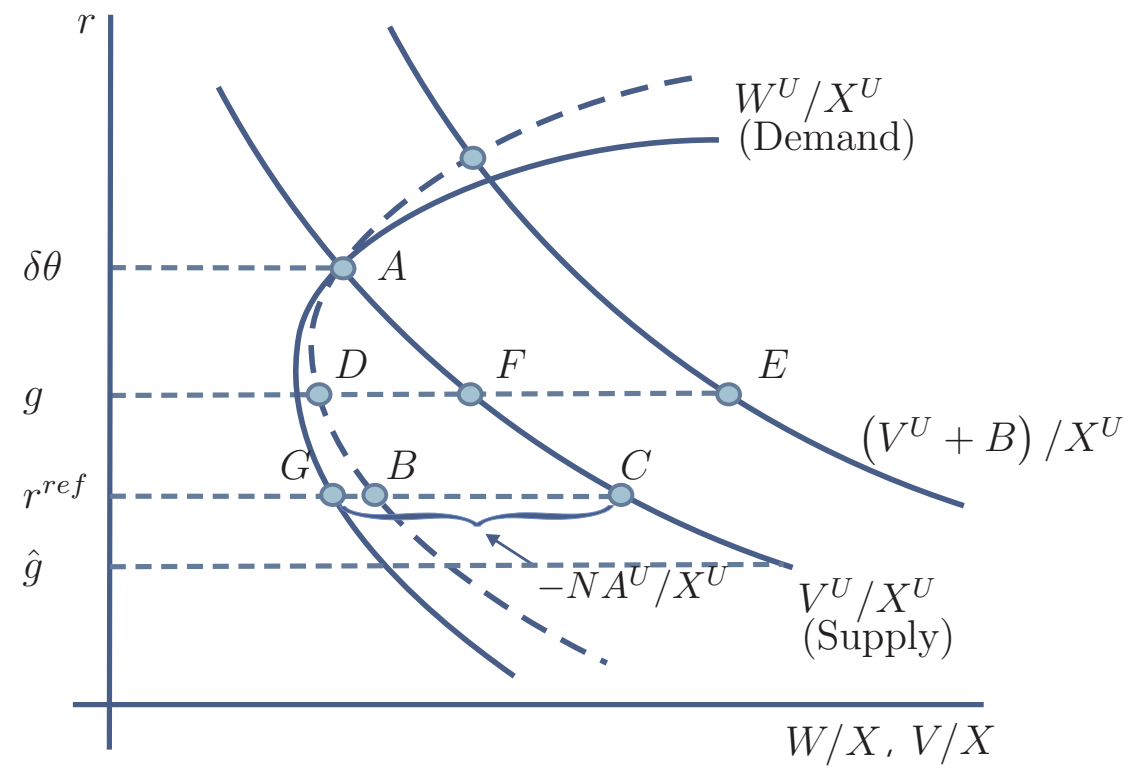

Figure 13: Long Run External Imbalances with Growth Slowdown when $\sigma=1$.

supply in the $M$ region, and hence endogenously reduce the effective asymmetry between the two regions. In terms of figure 12, the current account deficit contracts from $D-E$ to $D-F$, as the bubble collapses and inventories are accumulated, while it would contract from $D-E$ to $B-C$ in the benchmark no-inventory economy. Therefore, the inventory channel unambiguously leads to more rebalancing in the long run. We will see in the next section that this result can be overturned in the short run when $\sigma<1$.

\subsection{Long-Run Imbalances with a Growth Slowdown}

Let us now reintroduce the slowdown in growth. Under assumption 2, the asymptotic interest rate drops to $r^{r e f}$. Figure 13 describes what happens to $U^{\prime} s$ asymptotic external imbalances as growth declines. The asset demand curve rotates clockwise around point $A$, so that asset demand decreases in the relevant range $(r<\delta \theta)$.

The asymptotic net foreign asset position $N A^{U} / X^{U}=\left(W^{U}-V^{U}\right) / X^{U}$ can be read as the distance $G-C$. Since there are no inventories and $r=r^{r e f}$, it is the same as in the benchmark no-inventory economy and worsens as the growth rate $\hat{g}$ declines. Further, this asymptotic net foreign asset position is more negative with the growth slowdown $(G-C)$ than without $(D-F)$. The reason is that lower growth eliminates the buildup in commodity inventories and hence curtails the expansion in asset supply in the $M$ region. The inventory channel analyzed above, which reduces the asymetry between the two regions, is now damp- 
ened and the economy experiences less rebalancing in the long-run. However, since growth is also slower in the former case, the asymptotic current account may or may not worsen asymptotically with a growth slowdown. ${ }^{20}$

\section{Global Imbalances in the Short Run}

\subsection{Phase I: The Financial Crisis}

The behavior of the current account in the short run depends on the initial portfolios, the degree of home portfolio bias, and the degree of substitution between the commodity and the general consumption good. Following Caballero et al. (2008), we assume an extreme form of home bias: at $t=t_{0}$ all the assets held by the agents in the $U$ region are $U$ assets. Moreover, we assume that domestic residents' portfolios are proportional to the relative value of trees and bubbles. The assumption of extreme portfolio home bias is a good approximation. As of 2005, Sercu and Vanpee (2007) find that the degree of home equity bias varies between 0.5 for Norway and 0.90 for Japan. ${ }^{21}$ The assumption that domestic residents' portfolios are proportional to the relative value of trees and bubbles implies that $M$ has a significant exposure to $U^{\prime}$ s bubble asset. Again, this is a reasonable assumption. The onset of the U.S. subprime crisis was marked by the failure of a small German bank, IKB, and a few months later by the collapse of Northern Rock, a U.K. bank, highlighting the exposure of foreign investors to tainted U.S. assets. $^{22}$

Under these assumptions the degree of rebalancing on impact, $C A_{t_{0}^{+}}^{U}-C A_{t_{0}^{-}}^{U}$ is given by the sum of two terms: the adjustment in the trade balance $X_{t}^{U}-\theta W_{t}^{U}$, and the change in payments on external debt, through asset valuations and interest rates. The adjustment in payments on external debt is swamped by the adjustment in the trade balance when the external debt is initially small, so we focus on the latter.It is always positive and given by:

$$
T B_{t_{0}^{+}}^{U}-T B_{t_{0}^{-}}^{U}=-\theta\left(W_{t_{0}^{+}}^{U}-W_{t_{0}^{-}}^{U}\right)=\theta \mu_{t_{0^{-}}}\left(B_{t_{0}^{-}}+V_{t_{0}^{-}}^{U}-V_{t_{0}^{+}}^{U}\right)
$$

\footnotetext{
${ }^{20}$ The asymptotic current account deficit is now: $\frac{C A_{t}^{U}}{X_{t}^{U}} \underset{t \rightarrow \infty}{\sim} \frac{-\alpha \hat{g}}{\theta+\hat{g}-r^{r e f}}$ and decreases with $\hat{g}$.

${ }^{21}$ The degree of home equity bias is defined as one minus the ratio of the share of foreign equities in the domestic and world portfolios. It varies between zero (when the weight on foreign equities is given by their relative market capitalization) and one (when investors hold no foreign equities). It has declined in recent years, but remains very high for most countries.

${ }^{22}$ According to Beltran, Pounder and Thomas (2008), table 6, foreigners hold 39 percent $-\$ 2.3$ trillion out of $\$ 6$ trillion- of outstanding ABS backed by U.S. assets, and about 16 percent of all U.S. credit market instruments.
} 
where $\mu_{t_{0^{-}}}=W_{t_{0}^{-}}^{U} /\left(V_{t_{0}^{-}}^{U}+B_{t_{0^{-}}}\right)$represents the share invested in the domestic tree and the domestic bubble before the crash. $\mu_{t_{0^{-}}}<1$ when $U$ is a net debtor at time 0 . At impact, the direct effect of the bubble crash is a reduction in wealth $W_{t_{0}}^{U}$, which lowers consumption and improves the trade balance. ${ }^{23}$ Note that there is always less trade rebalancing in our economy than in the benchmark no-inventory economy. ${ }^{24}$ The change in the trade balance and the drop in $W_{t_{0}^{-}}^{U}-W_{t_{0}^{+}}^{U}$ are exactly proportional to the change in the value of the $U$ assets, $V_{t_{0}^{-}}^{U}+B_{t_{0^{-}}}-V_{t_{0}^{+}}^{U}$. As a starting point, note that when $\sigma=1$, the decline in asset prices is exactly the same in the economy with and without endogenous commodity prices:

$$
V_{t_{0}^{-}}^{U}+B_{t_{0^{-}}}-V_{t_{0}^{+}}^{U}=B_{t_{0^{-}}}\left(1-x_{t_{0}}^{U}\right) \geq 0
$$

where $x_{t_{0}}^{U}=X_{t_{0}}^{U} / X_{t_{0}}$ is the output share of $U$. This result is particular to the case $\sigma=1$ because the share of $X$-goods in consumption is invariant to the price $p_{t}$ of $Z$-goods. ${ }^{25}$

\subsection{Phase II: The Growth Slowdown}

Consider now the impact effects of the growth slowdown shock. We maintain the assumption of extreme home bias so that immediately before the growth slowdown shock hits, all of $U$ 's wealth is invested in $U$ assets. The adjustment in the trade balance is always positive:

$$
T B_{t_{1}^{+}}^{U}-T B_{t_{1}^{-}}^{U}=-\theta\left(W_{t_{1}^{+}}^{U}-W_{t_{1}^{-}}^{U}\right)=\theta \mu_{t_{1^{-}}}\left(V_{t_{1}^{-}}^{U}-V_{t_{1}^{+}}^{U}\right)
$$

where $\mu_{t_{1-}}=W_{t_{1}^{-}}^{U} / V_{t_{1}^{-}}^{U}$. The change in the value of $U$ assets can be computed as above. We show in Appendix A.1 that when $I_{t_{1}}$ is small and $\sigma=1$, the impact of the growth slowdown on the trade balance is negligible. By contrast, when $\sigma<1$, the decline in the value of $U$ assets is accentuated, and the trade balance improves at impact. We show in

\footnotetext{
${ }^{23}$ However, in equilibrium, the drop in wealth is dampened because interest rates plummet, raising the value of the good $U$-asset and making up for part of the drop in wealth.

${ }^{24}$ In Appendix A.2, we show that the difference in trade rebalancing between these two economies is strictly less than the direct effect of the change in terms of trade resulting from speculation in commodities, holding imports and exports constant. In other words, imported and exported quantities adjust by more in the endogenous commodity price economy than in the no-inventory economy.

${ }^{25}$ In contrast, we show in Appendix A.1 that in the more realistic $\sigma<1$ case, the increase in the price of the $U$-assets in response to the subprime shock, $V_{t_{0}^{+}}^{U}-V_{t_{0}^{-}}^{U}$, is larger when commodity prices are endogenous than when they are not. The reason for the larger increase in the value of $U$ assets is that the share of $X$-goods in value-added decreases, which raises asset demand relative to asset supply. As a result of this gap, asset supply has to increase by more in equilibrium. This "petrodollar" channel will prove crucial later on in our quantitative exercises. This effect is absent in the no-inventory benchmark economy, which would as a result experience a greater amount of rebalancing in the short run.
} 
the calibration section that most of this improvement originates in an improvement in the commodity component of the trade balance.

\subsection{Back-of-the-Envelope Calculations}

This section gauges the order of magnitude of the effects discussed above. We focus on the impact effect of the financial crisis, which we can develop analytically, and present in the next section discussion of the full dynamics. We find from this 'back-of-the-envelope' exercise that our model can explain much of the observed decline in real rates and rise in the price of oil in the first phase of the financial crisis, as well as the sharp collapse in the price of oil in the second phase. The model also goes a long way in explaining why the U.S. current account adjustment has been only minor so far, but it forecasts that the decline in the price of oil will reduce the trade deficit significantly in the future.

Phase I: The financial crisis. We begin with the impact of the crisis on interest rates. According to Figure 2, real interest rates declined by about 1.75 percent between September 2006, when house prices start to decline and the current account turns around, and June 2008. ${ }^{26}$ With a unit elasticity, $\sigma=1$, the change in interest rates is given by (15); when the elasticity of substitution $\sigma$ is smaller than 1 , the drop in interest rates $r_{t_{0}^{+}}-r_{t_{0}^{-}}$can still be expressed as the sum of two terms, a bubble-burst term reflecting the direct impact of the collapse of the bubble on asset supply and a commodity-price jump term reflecting the impact of the increase in the price of commodities on global asset supply and demand. ${ }^{27}$

The starting point in assessing the role of the two terms is an estimate of the size of the perceived losses generated by the financial crisis, in relation to the world's financial wealth: $B_{t_{0}^{-}} / W_{t_{0}^{-}}$. Estimates of the perceived size of the initial collapse of the bubble are difficult to come by, and necessarily imprecise. A key issue is that the endogenous response of interest rates offsets the impact of the crash in $B_{t}$ on global wealth. ${ }^{28}$ Empirically, this means that the estimates of the size of the initial bubble that we obtain are likely to be downward biased.

Direct losses in U.S. mortgage markets alone are estimated in the vicinity of $\$ 500$ billion (Greenlaw et al. (2008)). In its April 2008 Global Financial Stability Report, the International Monetary Fund reaches a similar estimate of the aggregate losses in the U.S. residential

\footnotetext{
${ }^{26}$ The world short real rate dropped from 1.6 percent to -0.9 percent. The U.S. long real rate drops from 2.4 percent to 1.4 percent.

${ }^{27}$ See Appendix A.3 for an expression for the commodity-price jump-term.

${ }^{28}$ For instance, we have seen that in the case of a unit elasticity $\sigma=1$, aggregate wealth remains unchanged.
} 
mortgage market (IMF (2008a)). Adding the potential losses to broader credit markets, the IMF calculates aggregate losses from writedowns of U.S. loans and securitized assets of about $\$ 945$ billion. $^{29}$ To these losses, one needs to add the declines in assets values generated by the broad process of deleveraging and the associated contraction in lending across markets. For instance, Greenlaw et al. (2008) estimate an overall $\$ 2.3$ trillion contraction in intermediary balance sheets. Moreover, mortgage market losses only reflect the increased rate of delinquencies on prime mortgages and commercial real estate (as well as the declining value of foreclosed properties). To this, one needs to add the decline in housing wealth for residential borrowers that remain in good standing on their mortgage. Estimates of the latter are significantly larger than the direct losses in mortgage markets. For instance, the Federal Reserve estimates household's housing wealth at $\$ 19.6$ trillion dollars as of June $2006 .{ }^{30}$ According to the Case-Shiller U.S. composite-10 Home Price index, U.S. housing prices declined 18 percent in nominal terms between September 2006 and June 2008 (see figure 4). Assuming that this decline is across the board would wipe out at least an additional $\$ 3.5$ trillion in U.S. housing wealth alone. ${ }^{31}$

Adding these estimates yields a total loss in U.S. housing wealth and mortgage markets in the range of $\$ 2$ to $\$ 4$ trillion. What is relevant in our calculation is the ratio of these initial losses to the world's financial wealth $W_{t_{0}^{-}}$. We construct a crude estimate of the latter at the onset of the crisis as the sum of the U.S. household net worth of $\$ 51.7$ trillion at the end of 2005, and an estimate of the financial wealth of the rest of the world of $\$ 80.7$ trillion. ${ }^{32}$ This would give an initial size of the bubble between 1.5 and 3.0 percent of the world's financial wealth. In what follows, we assume an initial bubble equal to 2 percent of the world's financial wealth.

It is immediate that the bubble-burst term in equation (15), equal to $-g B_{t_{0}^{-}} / W_{t_{0}^{-}}$, is relatively small. With a growth rate around 3 percent, it is equal to only -0.06 percent. On

\footnotetext{
${ }^{29}$ In its October 2008 report, the IMF revised its estimate of U.S. declared losses on loans and securitized assets to $\$ 1.4$ trillion (IMF (2008b)).

${ }^{30}$ See table B.100 of the June 2008 release of the Flow of Funds.

${ }^{31}$ This is calculated under the extreme assumption that all mortgage market losses are housing market losses. Of course, foreclosures and reposessions generate additional losses beyond the decline in housing values.

${ }^{32}$ See Table B.100 of the June 2008 issue of the Federal Reserve's Flow of Funds Accounts for the US figure. To obtain the estimate of the financial wealth of the rest of the world in 2006, we calculate the ratio of output to financial wealth for the United States, the European Union and Japan between 1982 and 2004. We find a GDP-weighted average of 2.48 (see Caballero et al. (2008) for additional details). We apply this ratio to the GDP of the rest of the world in 2005 and obtain $\$ 80.7$ trillion. To the extent that many countries are less financially developed than the U.S., Europe or Japan, we are likely to overstate the world's financial wealth. This would further bias downward our estimate of $B_{t_{0}} / W_{t_{0}}$.
} 


\begin{tabular}{|c|c|c|c|c|c|c|}
\hline & \multicolumn{5}{|c|}{$\overline{p_{t_{0}^{+}} / p_{t_{0}^{-}}}$} \\
\hline & & 1 & 1.2 & $1.5^{\circ}$ & 2 & 3 \\
\hline \multirow{5}{*}{$\sigma:$} & 0.05 & -2.22 & -2.23 & -2.25 & -2.28 & -2.37 \\
\hline & 0.1 & -1.02 & -1.04 & -1.08 & -1.16 & -1.33 \\
\hline & 0.2 & -0.44 & -0.48 & -0.55 & -0.69 & -1.00 \\
\hline & 0.5 & -0.12 & -0.21 & -0.37 & -0.66 & -1.27 \\
\hline & 1 & -0.06 & -0.23 & -0.50 & -0.93 & -1.80 \\
\hline
\end{tabular}

Table 1: Decline in world interest rates (percent). The table reports the initial drop in interest rates $r_{t_{0}^{+}}-r_{t_{0}^{-}}$. Source: Authors Calculations.

the other hand, the commodity-price jump term can be substantial. To see this, Table 1 reports estimates of the decline in $r$ for different values of the elasticity of substitution $\sigma$ and different estimates of the increase in commodity prices. The calculation of the commodityprice-jump term requires an estimate of average expenditure share of commodities, $s_{z t_{0}^{-}}$. In the table, we assume that $s_{z t_{0}^{-}}=0.04$ percent, which corresponds to the average share of oil expenditures in world GDP in 2005 and $2006 .^{33}$

Between September 2006 and June 2008 the real price of a barrel of West Texas Intermediate increased from $\$ 68.5$ to $\$ 142.3$ in constant 2008 prices (see Figure 7 ). Interpreting this surge as the direct effects of the crisis yields $p_{t_{0}^{+}} / p_{t_{0}^{-}}=2.08$. The associated decrease in real interest rates in table 1 is consistent with what we see in the data. For a realistically low level of the short-term price elasticity of demand $\sigma=0.1$, we find a decline in interest rates of 1.16 percent, smaller than the 1.75 percent observed over that period, but much larger than the 0.06 percent decline associated with the direct effect of the collapse of the bubble. Most of the decline in interest rates comes from the indirect effect of higher commodity prices, hinting that the endogenous response of commodity prices to the subprime crisis is critical in understanding the global macroeconomic environment.

We now turn to the effect of the crash on commodity prices. We can compute the decline in $U^{\prime} s$ financial wealth and find an expression for the jump in commodity prices as a function

\footnotetext{
${ }^{33}$ According to the Energy Information Administration (Table 2.4, World Petroleum Demand), world demand for oil in 2005 was 83,646 thousand barrels per day. With a WTI price of the barrel equal to $\$ 56.64$ dollars, this corresponds to $\$ 1.7$ trillion, or 3.79 percent of world GDP. In 2006, the share of oil in expenditures was 4.16 percent. The remaining parameters will be discussed in more detail in Section 4.2.
} 


\begin{tabular}{|c|c|c|c|c|c|c|}
\hline \multicolumn{7}{|c|}{$\frac{\text { Change in commodity prices, } p_{t_{0}^{+}} / p_{t_{0}^{-}}}{B_{-} / W_{-} \text {(prcent) }}$} \\
\hline \multirow{5}{*}{$\sigma$} & & 1 & 2 & 3 & 4 & 5 \\
\hline & 0.05 & 1.11 & 1.91 & 2.73 & 3.57 & 4.42 \\
\hline & 0.1 & 1.11 & 1.98 & 2.89 & 3.83 & 4.80 \\
\hline & 0.2 & 1.13 & 2.16 & 3.30 & 4.53 & 5.83 \\
\hline & 0.5 & 1.21 & 3.42 & 6.76 & 11.22 & 16.81 \\
\hline
\end{tabular}

Table 2: The effect of the subprime crisis on commodity prices. The table reports the initial increase in the price of commodities $p_{t_{0}^{+}} / p_{t_{0}^{-}}$. Source: Authors Calculations.

of the decline in $U^{\prime} s$ wealth and the size of the original collapse of the bubble: ${ }^{34}$

$$
\frac{p_{t_{0}^{+}}}{p_{t_{0}^{-}}}=\left[1+\frac{W_{t_{0}^{+}}^{U}-W_{t_{0}^{-}}^{U}}{X_{t_{0}}^{U}} \frac{\theta}{\mu_{t_{0}^{-}}} \frac{1-s_{z t_{0}^{-}}}{s_{z t_{0}^{-}}}+\frac{1}{s_{z t_{0}^{-}}}\left(\frac{1}{x_{t_{0}}^{U}}-1\right) \frac{B_{t_{0}^{-}}}{W_{t_{0}^{-}}}\right]^{1 /(1-\sigma)} .
$$

We already have an estimate for $B_{t_{0}^{-}} / W_{t_{0}^{-}}$and $s_{z t_{0}^{-}}$. We estimate the decline in U.S. financial wealth $W_{t_{0}^{+}}^{U}-W_{t_{0}^{-}}^{U}$ from the Federal Reserve Flow of Funds Accounts. Between June 2007 and March 2008, U.S. households financial wealth declined $\$ 1.65$ trillion, or 12 percent of output. ${ }^{35}$ Next, we construct an estimate of $\mu_{t_{0}^{-}}$, the share of domestic financial wealth invested in the domestic tree and the domestic bubble before the crash. In 2005, the net foreign liabilities of the U.S. amounted to $\$ 1.85$ trillion, or 15 percent of U.S. GDP. ${ }^{36}$ This corresponds to $\left(W_{t_{0}^{-}}^{U}-V_{t_{0}^{-}}^{U}-B_{t_{0}^{-}}\right) / X_{t_{0}}^{U}$. Substituting the expression for $\mu_{t_{0}^{-}}$, and using the fact that $W_{t_{0}^{-}}^{U} / X_{t_{0}^{-}}^{U}=4.16$, we obtain $\mu_{t_{0}^{-}}=0.96 .{ }^{37}$ Finally, we set the ratio of U.S. to world output in 2005 at approximately $0.25 .^{38}$ Table 2 reports estimates of the increase in commodity prices as a function of the elasticity $\sigma$ and the size of the initial bubble collapse $B_{t_{0}^{-}} / W_{t_{0}^{-}}$.

The results in Table 2 support our view that the collapse in the U.S. housing market and the contraction in credit markets played a significant role in explaining the surge in

\footnotetext{
${ }^{34}$ See Appendix A.1.

${ }^{35}$ See Table B.100 of the June 2008 Federal Reserve Flow of Funds estimates. Households net worth was $\$ 57.6$ trillion in June 2007 at the onset of the crisis and only $\$ 55.9$ trillion in March 2008 .

${ }^{36}$ From Table 2 of the BEA's International Investment Position. The net asset position is estimated at market value.

${ }^{37}$ This represents an overestimate of the share of U.S. assets held by U.S. investors since we assume an extreme form of home bias.

${ }^{38}$ US GDP in 2005 was $\$ 12.4$ trillion, while the world's GDP was about $\$ 45$ trillion. While the theoretical model refers only to $U$ and $M$, in this back of the envelope exercise and the simulations that follow, it is natural to include other countries as part of $M$.
} 
Change in the Trade Balance, $\left(T B_{t_{0}^{+}}^{U}-T B_{t_{0}^{-}}^{U}\right) / X_{t_{0}}^{U}$ (percent):

\begin{tabular}{ccccccc}
\hline & \multicolumn{5}{c}{$B_{t_{0}^{-}} / W_{t_{0}^{-}}$(percent): } \\
& 1 & 2 & 3 & 4 & 5 \\
\cline { 2 - 6 }$p_{t_{0}^{+}} / p_{t_{0}^{-}}:$ & 1.01 & 6.02 & 9.04 & 12.05 & 15.06 \\
& 1.5 & 2.30 & 5.31 & 8.32 & 11.33 & 14.34 \\
& 1.24 & 4.26 & 7.27 & 10.28 & 13.29 \\
& -0.47 & $\mathbf{2 . 5 5}$ & 5.56 & 8.57 & 11.58 \\
& 3 & -3.77 & -0.75 & 2.26 & 5.27 & 8.28 \\
\hline
\end{tabular}

Table 3: The effect of the subprime crisis on the trade balance (percent). The table reports the initial change in the trade balance relative to output, $\left(T B_{t_{0}^{+}}^{U}-T B_{t_{0}^{-}}^{U}\right) / X_{t_{0}}^{U}$. Source: Authors Calculations.

commodity prices that followed the subprime crisis. We find that, for our benchmark estimate of the size of the bubble of 2 percent, commodity prices increase by 98 percent, when the short run elasticity of substitution equals 0.1 , which is very close to the 108 percent observed in the data. Recall that without an asset-channel (no-inventories benchmark), commodity prices would not jump when the crisis occurs.

Turning to the external accounts, between September 2006 and June 2008, the U.S. trade deficit on goods and services improved from $\$ 793$ billion to $\$ 710$ billion (annualized), an improvement that represents 1.02 percent of U.S. GDP. ${ }^{39}$ Can the model explain this very limited rebalancing? We answer this question by rewriting the trade balance equation (19) as:

$$
\frac{T B_{t_{0}^{+}}^{U}-T B_{t_{0}^{-}}^{U}}{X_{t_{0}}^{U}}=\frac{\mu_{t_{0}^{-}}}{1-s_{z t_{0}^{-}}}\left[\frac{B_{t_{0}^{-}}}{W_{t_{0}^{-}}}\left(\frac{1}{x_{t_{0}}^{U}}-1\right)-s_{z t_{0}^{-}}\left(\left(\frac{p_{t_{0}^{+}}}{p_{t_{0}^{-}}}\right)^{1-\sigma}-1\right)\right]
$$

The first term inside the brackets represents the direct impact of the collapse of the bubble on the trade balance. It contributes positively to global rebalancing. The second term reflects the contribution of commodity prices. Table 3 reports the sum of the direct and indirect impacts of the subprime crisis on the trade balance as a function of the commodity price surge $p_{t_{0}^{+}} / p_{t_{0}^{-}}$and the size of the initial bubble $B_{t_{0}^{-}} / W_{t_{0}^{-}}$for an elasticity of substitution $\sigma$ equal to 0.1 .

The first line of the table reports the change in the trade balance in the benchmark noinventory economy (which coincides with the direct effect). We find a large and implausible improvement in the trade balance. For instance, for an initial bubble equal to 2 percent of world financial wealth, the no-inventory economy predicts a 6.02 percent improvement in

\footnotetext{
${ }^{39}$ See the Bureau of Economic Analysis's National Income Accounts, Table 4.1.
} 
Change in commodity prices, $p_{t_{1}^{+}} / p_{t_{1}^{-}}$:

\begin{tabular}{cccccc}
\hline & & \multicolumn{3}{c}{$\left(W_{t_{1}^{+}}^{U}-W_{t_{1}^{-}}^{U}\right) / X_{t_{1}}^{U}$ (percent): } \\
& & -0.05 & -0.10 & -0.15 & -0.17 \\
\cline { 3 - 6 }$\sigma:$ & 0.05 & 0.44 & 0.17 & 0.07 \\
& 0.1 & 0.70 & $\mathbf{0 . 4 2}$ & 0.16 & 0.06 \\
& 0.2 & 0.67 & 0.38 & 0.12 & 0.04 \\
& 0.5 & 0.53 & 0.21 & 0.03 & 0.01 \\
\hline
\end{tabular}

Table 4: The effect of the growth slowdown on commodity prices. The table reports the drop in the price of commodities $p_{t_{1}^{+}} / p_{t_{1}^{-}}$for different values of the decline in US financial wealths. Source: Authors Calculations.

the trade balance relative to output. This is a far cry from the 1.02 percent observed in the data. Again, once we introduce the "petrodollar" channel, the required rebalancing drops significantly. For instance, the trade balance improves 'only' by 2.55 percent, instead of 6.02 percent when commodity prices double. If instead, we consider a tripling of commodity prices, or a smaller initial bubble collapse, it is possible for the trade balance to worsen on impact. While our preferred numbers are on the high side (2.5 percent against 1.02), it is apparent that the model has the capacity to rationalize the very limited global rebalancing that we are witnessing. ${ }^{40}$

All in all, we conclude that the model is in the right ballpark and can account for the broad features of the global economy in the first phase of the crisis.

Phase II: The growth slowdown. We now ask whether the model can account for the broad features of the data following the slowdown in economic activity. In real terms, between July and November 2008, oil prices declined by 53 percent (see figure 7). We can use (21) to write the change in commodity prices as:

$$
\frac{p_{t_{1}^{+}}}{p_{t_{1}^{-}}}=\left[1+\frac{W_{t_{1}^{+}}^{U}-W_{t_{1}^{-}}^{U}}{X_{t_{1}}^{U}} \frac{\theta}{\mu_{t_{1}^{-}}} \frac{1-s_{z t_{1}^{-}}}{s_{z t_{1}^{-}}}\right]^{1 /(1-\sigma)} .
$$

The change in commodity prices is a function of the drop in U's financial wealth. Reasonable estimates of the financial losses incurred since July 2008 are not available yet. Instead, table 4 reports predicted declines for a range of estimates of $\left(W_{t_{1}^{+}}^{U}-W_{t_{1}^{-}}^{U}\right) / X_{t_{1}}^{U}$ and different values of the short run demand elasticity for commodities.

\footnotetext{
${ }^{40}$ Calculations for the current account are very similar since when $\mu_{t_{0}^{-}}$is close to 1 , interest payments remain small.
} 
Change in the Trade Balance

\begin{tabular}{ccccc}
\hline & \multicolumn{3}{c}{$\left(W_{t_{1}^{+}}^{U}-W_{t_{1}^{-}}^{U}\right) / X_{t_{1}}^{U}$ (percent): } \\
& -0.05 & -0.1 & -0.15 & -0.17 \\
\cline { 2 - 5 }$\left(T B_{t_{1}^{+}}^{U}-T B_{t_{1}^{-}}^{U}\right) / X_{t_{1}}^{U}$ (percent): & 1.09 & $\mathbf{2 . 1 8}$ & 3.27 & 3.70 \\
\hline
\end{tabular}

Table 5: The effect of a growth slowdown on the trade balance (percent). The table reports the initial change in the trade balance relative to output, $\left(T B_{t_{1}^{+}}^{U}-T B_{t_{1}^{-}}^{U}\right) / X_{t_{1}}^{U}$. Source: Authors Calculations.

It is immediate that commodity prices are extremely sensitive to the drop in financial wealth. For $\sigma=0.1$, a modest decline in U.S. financial wealth representing $10 \%$ of output triggers a staggering 58 percent $(0.42-1)$ decline in commodity prices. This is remarkably close to the 53 percent decline observed in the data.

Table 5 reports the predicted change in the trade balance as a function of the decline in U.S. financial wealth. Since $T B^{U}=X^{U}-\theta W^{U}$, this calculation is independent from $\sigma$. This part of the analysis is necessarily more speculative. It indicates that the model predicts a significant rebalancing of the trade balance, equal to about 2.2 percent of output, as a consequence of the growth slowdown.

\section{Calibration and Dynamics}

We now turn to the analysis of full general equilibrium dynamic simulations. We begin with a discussion of plausible short run and long run elasticities of demand for commodities. We then present the results from dynamic simulations of the financial crisis with and without growth slowdown.

\subsection{Short and Long Run Elasticity}

A key parameter of our model is the elasticity of substitution $\sigma$. Nordhaus (1980) finds low 'apparent' short run price elasticities of demand, around 0.3, at the time of the 1973 oil price shock. Long run elasticities are typically higher since it takes time to substitute away from energy-intensive technology. Nordhaus (1980) notes that for many components of the physical capital stock, energy-substitution is only possible when the existing capital is scrapped. In the transportation sector for instance, in which energy consumption depends 
in large part on the fuel efficiency of the outstanding stock of vehicles, energy consumption responds gradually as old vehicles are slowly replaced with more fuel efficient ones. Similarly, in the case of electricity generation, there is almost no possibility for substitution in the short run. In the long run, on the other hand, electricity generation can switch to other methods of production such as nuclear or wind power generation.

More recent studies confirm the 'crude' estimates in Nordhaus (1980) for the short run while finding higher long run estimates. ${ }^{41}$ The typical estimates for short run price elasticities vary between 0.1 and 0.3 while long run estimates vary between 0.4 and $1 .{ }^{42}$

Table 6 provides an update on Nordhaus (1980)'s apparent price elasticity estimates around the recent increase in oil prices. It reports recent data on U.S. petroleum consumption and prices before and after 2003, where the break in oil prices is apparent in figure 7 . Between 2003 and 2007 petroleum prices increased by 8.55 percent per year, a sharp break from the 1.44 percent annual increase between 1988 and 2003. Nevertheless, the growth in demand for petroleum products slowed only from 0.84 percent to 0.61 percent. The 'apparent' price elasticity is calculated as in Nordhaus (1980), under the assumption of a unit elasticity of petroleum product demand to GDP, as the (opposite of the) percentage slowdown in energy demand corrected for the percentage change in real output growth, divided by the percentage acceleration in prices. ${ }^{43}$ We obtain an estimate of 0.04 , on the low end of available empirical estimates. ${ }^{44}$ This is consistent with recent empirical estimates that find an even smaller short run price elasticity now than in the 1970s. ${ }^{45}$

A simple way of capturing this time variation in $\sigma$ is to assume that the elasticity of substitution remains significantly smaller than one until the share of expenditures on the $Z$-good reaches a certain exogenous level $\bar{s}_{z}$. When that level is reached, we assume that the elasticity of substitution becomes equal to 1 . This transition is fully anticipated by economic agents. Continuity of the demand schedule also requires that $\alpha$ differ as we transition from

\footnotetext{
${ }^{41}$ See Roy, Sanstad, Sathaye and Khaddaria (2006) or Dahl and Sterner (1991) for an older survey.

${ }^{42}$ See Hamilton (2008) for a recent discussion of crude oil prices, and the references therein.

${ }^{43}$ The income elasticity of petroleum demand is largely irrelevant in these calculations since output growth was essentially the same over both subperiods. The income elasticity of demand of industrial countries has declined significantly since the oil price shocks of the 1970s and is now closer to 0.5. However, the income elasticity of emerging and oil producing countries appears to be much closer or above unity. See Gately and Huntington (2002) and the discussion in Hamilton (2008).

${ }^{44}$ Interestingly, the same (unreported) calculations for residential demand for petroleum products yields a much larger apparent elasticity, at 0.78 . The price elasticity is lowest for the industrial and transport sectors, close to 0 .

${ }^{45}$ Hughes, Knittel and Sperling (2008) find a short run price elasticity between 0.03 and 0.08 between 2001 and 2006.
} 
U.S. Petroleum Demand and Apparent Price Elasticities

Growth in real GDP (percent)

\begin{tabular}{cc}
$1988-2003$ & $2003-07$ \\
\hline 2.83 & 2.90
\end{tabular}

Growth in real petroleum product prices (percent)

1.44

8.55

Growth in real petroleum product demand (percent)

0.84

0.61

Apparent price elasticity

0.04

Table 6: U.S. Petroleum Demand and Apparent Price Elasticity. Source: Annual Energy Review, EIA, Tables 1.5, 3.1, 3.4, Monthly Energy Review, EIA, Tables 2.1-2.6. Consumer Price Estimate for Petroleum before 2005; Fossil Fuel Composite Price after 2005. All growth rates are compound annual averages. The apparent elasticity is calculated under the assumption of a unit sectoral elasticity with respect to GDP.

$\sigma<1$ to $\sigma=1{ }^{46}$ We denote $\alpha^{\prime}$ the preference parameter after the switch to $\sigma=1$.

\subsection{The Dynamic System and the U.S. Financial Shock.}

We now characterize the full dynamic path in response to a U.S. financial collapse. We start the economy on the dynamic path of the bubble equilibrium with $\sigma<1$, and a given level of global imbalances. At $t=t_{0}$, the bubble collapses and the economy jumps to the dynamic path of the bubbleless equilibrium. We refer the reader to appendix B for a complete exposition of the dynamic system and the transitions that occur between the different regimes.

The calibration of the dynamic path requires that we provide values for the following parameters: the capitalization ratio $\delta$, the growth rate of the economy $g$, the relative size of $U$ and $M$, the elasticity of substitution $\sigma$, the propensity to consume out of financial wealth $\theta$ as well as the share of commodity expenditures $\bar{s}_{z}$ when the elasticity of substitution becomes unitary. We adopt a mixed approach, setting the value of some parameters based on plausible values, and calibrating others so as to reproduce key features of the data.

We start by setting the growth rate of the $X$-good to $g=0.03$, which is close to the real output growth rate in the U.S. between 1950 and 2007 (3.28\%). As discussed above, we assume that $U$ represents a quarter of the world's output. We set the elasticity of substitution to $\sigma=0.3$. This is significantly larger than the apparent elasticity estimate in Table 6. Nonetheless, as argued above, it is well within the range of estimates in the

\footnotetext{
${ }^{46}$ To see this, suppose that the transition occurs at some time $T$. Aggregate demand for good $X$ right before $T$ is given by $W_{T^{-}}=\left(1+\alpha p_{T}^{1-\sigma}\right) X_{T}$. Right after the switch, it is equal to $W_{T^{+}}=\left(1+\alpha^{\prime}\right) X_{T}$. Continuity of commodity prices and wealth requires $\alpha p_{T}^{1-\sigma}=\alpha^{\prime}$.
} 
empirical literature. Furthermore, this value of $\sigma$ produces realistic levels of adjustment in commodity prices in the model. It also implies that the price of commodities increases initially at $g / \sigma=10 \%$ in the equilibrium with bubble, accounting for some of the rapid increase in commodity prices observed before the U.S. financial crisis.

We set $\bar{s}_{z}=0.1$, so that the long run model kicks in when the expenditure share of commodities reaches 10 percent. This seems a reasonably high value. In the data, the share of oil in world output reached 4.16 percent in 2006, up from 1.29 percent in 1998. In the simulation, it would take around 10 years before the expenditure share reaches 10 percent. This yields $\alpha^{\prime}=11.11 \%$. Finally, we set the value of the world capitalization index $\delta$ to 0.15 , which corresponds to about half of the share of capital in national accounts. As discussed in Caballero et al. (2008), $\delta$ should be substantially lower than the capital share since many forms of capital do not generate capitalizable streams of revenue. ${ }^{47}$ We then calibrate each countries' $\delta$ so as to stabilize global imbalances before the crisis erupts. We obtain $\delta^{U}=0.144$ and $\delta^{M}=0.1520{ }^{48}$

The two remaining parameters to calibrate are $\theta$ and $\alpha$. We set their value so as to control (a) the size of the initial bubble relative to aggregate wealth at $t=0, B_{0} / W_{0}=\beta_{0}$; and (b) the limit size of the bubble that would emerge in the bubbly equilibrium under $\sigma=1$, $\beta_{1} \equiv \lim _{t \rightarrow \infty} B_{t} / W_{t}$. From equation (B.1), we obtain $\lim _{t \rightarrow \infty} B_{t} / W_{t}=1-\delta \theta / g\left(1+\alpha^{\prime}\right)$. For given values of $\beta_{0}$ and $\beta_{1}$, we infer back the corresponding values of $\theta$ and $\alpha$.

In practice, we set $\beta_{0}=0.02$, so that the collapse of the bubble represents roughly $2 \%$ of world's wealth, as estimated in the previous section. We set $\beta_{1}=1.01 \beta_{0}$, so that the economy is not far from its long run steady state when the bubble collapses (this ensures that the share of commodities in expenditures is not too small). We obtain $\theta=0.22$ and $\alpha=0.40$. We view these values as plausible. As a point of reference, Caballero et al. (2008) computed a value of $\theta=0.25$, using data on U.S. household sector net worth and U.S. GDP ( $\theta$ can be interpreted as the output to financial wealth ratio). These values imply that the economy is slightly dynamically inefficient since $\delta \theta /\left(1+\alpha^{\prime}\right)=2.94 \%<g=3 \%$. Finally, we set $\eta=-0.15$, in line with estimates of the U.S. net external debt position in 2006. Table 7 summarizes all the parameter values.

\footnotetext{
${ }^{47}$ Caballero et al. (2008) assumed $\delta=0.12$. The results are largely unchanged with $\delta=0.12$.

${ }^{48}$ While the calibration sets $\delta^{U}$ slightly lower than $\delta^{M}$, the 'perceived' capitalization index in $U$ in presence of the bubble $B$ is much larger, equal to $\hat{\delta}^{U}=\left(\delta-\left(1-x_{t_{0}}^{U}\right) \delta^{M}\right) / x_{t_{0}}^{U}=0.156$. In that sense, the calibration is 'extreme' in that it assumes that $U$ does not have any fundamental advantage in supplying stores of value.
} 


\begin{tabular}{|c|c|c|c|c|c|c|c|c|}
\hline \multirow[b]{2}{*}{$\begin{array}{l}\text { Parameter } \\
\text { Value }\end{array}$} & \multicolumn{8}{|c|}{ Main Parameters } \\
\hline & $\begin{array}{c}g \\
0.03\end{array}$ & $\begin{array}{c}\sigma \\
0.3\end{array}$ & $\begin{array}{c}X^{u} / X \\
0.25\end{array}$ & $\begin{array}{c}\bar{s}_{z} \\
0.1\end{array}$ & $\begin{array}{c}\delta \\
0.15\end{array}$ & $\begin{array}{l}\beta_{0} \\
2 \%\end{array}$ & $\begin{array}{c}\beta_{1} \\
2.02 \%\end{array}$ & $\begin{array}{c}\eta \\
-0.15\end{array}$ \\
\hline & \multicolumn{8}{|c|}{ Inferred Parameters } \\
\hline Parameter & $\alpha$ & $\theta$ & $\delta^{U}$ & $\delta^{M}$ & & & & \\
\hline Value & 0.40 & 0.22 & 0.144 & 0.152 & & & & \\
\hline
\end{tabular}

Table 7: Main Parameters. See text for description.

Figure 14 reports the simulation obtained with these parameter values. Before the crisis, the real interest rate is slightly above $3.4 \%$ and increasing, commodity prices (normalized) are equal to their steady state value $\hat{q} \equiv(\alpha / Z)^{1 / \sigma}$, while both the trade balance and current account are in deficit and improving (-3.5\% and $-4 \%$ of output, respectively).

At $t=0$, the financial crisis hits, wiping out $2 \%$ of aggregate financial wealth. The response of interest rates is quite stark (panel A): they drop from about 3.5 percent to 2.7 percent. This decline in interest rates is much larger than the one obtained in the benchmark economy (the dashed line in panel A), where the decline is a mere 6 basis points. The fall in interest rates in our economy is strong enough to trigger inventory accumulation. As panel B shows, the normalized price of commodities $\hat{q}_{t}=p_{t} / X_{t}^{1 / \sigma}$ jumps 2.3 times and gradually converges back over the next 12 years. By contrast, in the benchmark economy, the (normalized) price of commodities remains unchanged and equal to $\hat{q} .{ }^{49}$ The jump in prices lowers the demand for commodities and allows inventory accumulation. We find that, starting from $I_{t_{0}}=0$, inventories rise relatively slowly: it takes 12 years before their market value $p I$ peaks at $3.2 \%$ of world financial wealth. In the initial periods after the shock, in particular, inventories remain very low, not contributing much to the global supply of assets.

Panel D reports the current account relative to output in our economy and the benchmark economy. In both cases, the current account improves as a result of the collapse of the bubble. However, as conjectured in the previous section, the rebalancing is much smaller in the economy with inventories. In the benchmark economy, the current account jumps from $-4 \%$ to $2 \%$, an instant rebalancing of $6 \%$ of GDP. This is not surprising, given the fact that the bubble is located in the US: the reduction in asset supply leads agents to move part of

\footnotetext{
${ }^{49}$ This still implies that in the benchmark economy $p_{t}$ increases at the rate $g / \sigma$, faster than the rate of economic growth.
} 
Change in U.S. Trade Balance, 1980-1989 and 1999-2008

\begin{tabular}{lccccc} 
percent of GDP & $1980-1987$ & $1987-1989$ & & $1999-2006$ & $2006-2008$ \\
\cline { 2 - 3 } \cline { 5 - 6 } $\begin{array}{l}\text { Change in the trade balance: } \\
\text { of which: }\end{array}$ & -2.5 & 1.5 & & -2.8 & 0.8 \\
change in non-oil BGS: & -4.4 & 1.5 & & -1.4 & 1.5 \\
change in oil balance: & 1.9 & 0.0 & & -1.4 & -0.7 \\
\hline
\end{tabular}

Table 8: Change in the US Trade Balance, 1980-1989 and 1999-2008. Source: Bureau of Economic Analysis.

their financial investments to $M$. By contrast, in our economy, the rebalancing is 'only' from $-4 \%$ to $-1.4 \%$. As we discussed earlier, this is larger than the rebalancing observed in the data, but of a similar order of magnitude.

Eventually, the rebalancing must become larger in our economy, with a long run current account deficit of $-0.6 \%$ against $-0.9 \%$ in the benchmark no-inventory economy. Nevertheless, the role of commodities is to stabilize capital outflows for the first four years after the initial shock. Panel E shows that the implications for the trade balance are very similar, as discussed earlier. Panel $\mathrm{F}$ further decomposes the trade balance into its non-commodity component $\left(X_{t}^{U}-\theta W_{t}^{U} /\left(1+\alpha p_{t}^{1-\sigma}\right)\right)$ and its commodity component $\left(-\alpha p_{t}^{1-\sigma} \theta W_{t}^{U} /\left(1+\alpha p_{t}^{1-\sigma}\right)\right)$. Underlying the muted response of the trade balance, both the commodity and non-commodity balances adjust sharply. The commodity balance goes from $-4.6 \%$ to $-7.9 \%$ of output, while the non-commodity balance jumps from $1.0 \%$ to $6.9 \%$ of output.

This asymmetric response of the commodity and non-commodity component of the trade balance is consistent with the empirical evidence. Table 8 reports the change in the U.S. trade balance during the last two rebalancing episodes: 1987-1989 and 2006-2008. ${ }^{50}$

The table shows that the recent improvement in the U.S. trade balance comes entirely from the non-oil component, which improved more than 1.5 percent of GDP. By contrast, the oil balance worsened by 0.7 percent of GDP. Comparing this rebalancing episode with the previous episode, centered around 1987, it is striking to note that oil prices played no role in attenuating the external rebalancing then: the deficit of the oil balance did not change between 1987 and 1989 .

\footnotetext{
${ }^{50}$ Milesi-Ferretti (2008) presents additional evidence on the contrast between the two episodes.
} 


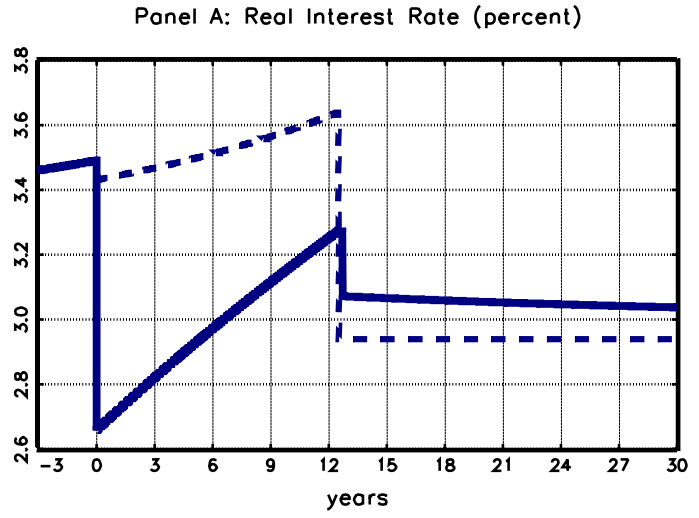

Panel C: $p * 1 / w$

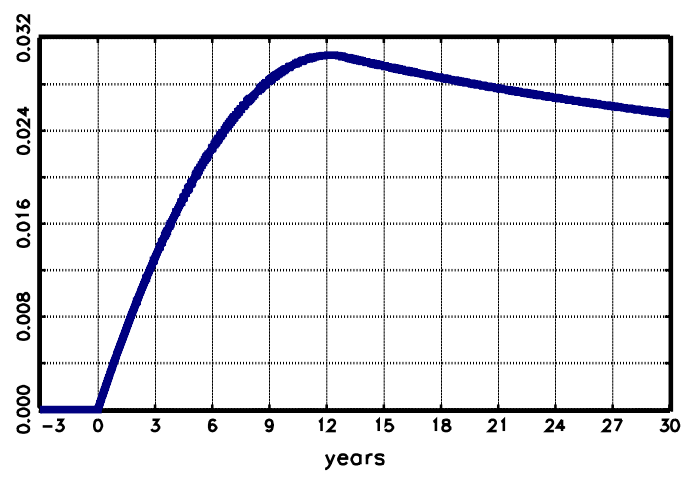

Panel E: TB/X, U-region

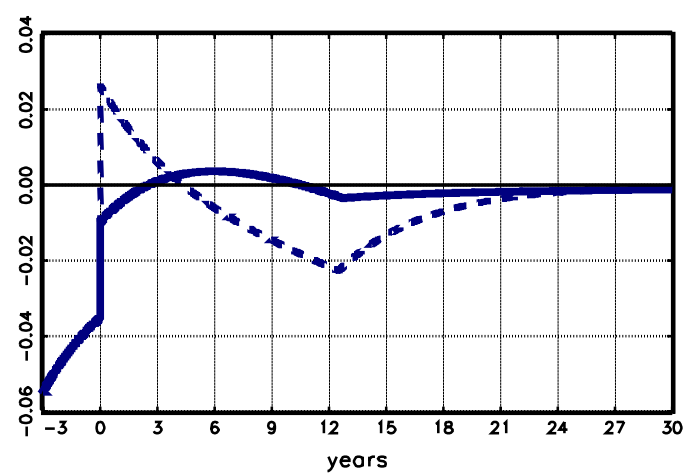

Panel B: normalized commodity prices

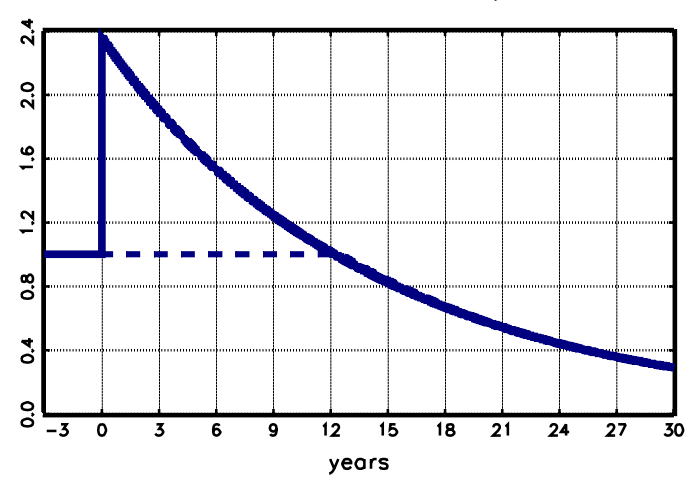

Ponel D: CA/X, U-region

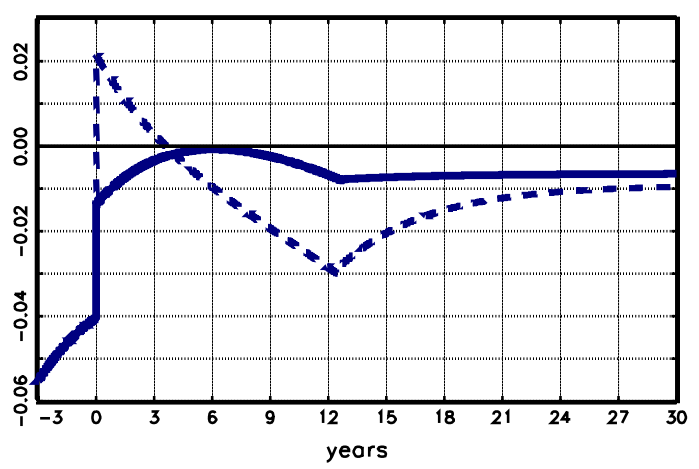

Ponel F: Decomposition of TB/X

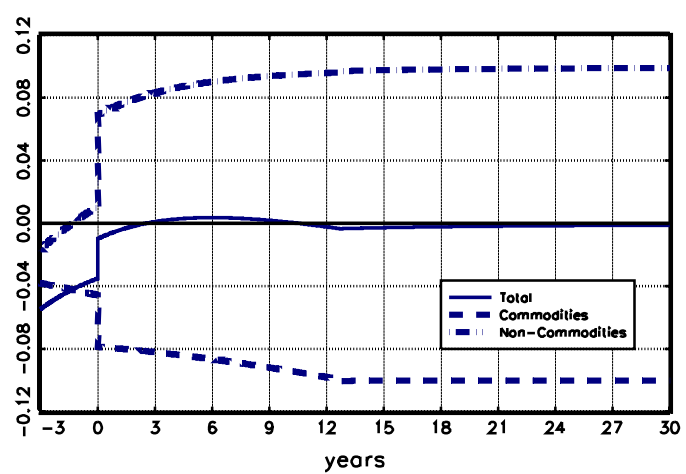

Figure 14: The Dynamic Response to the Subprime Crisis. Short Run and Long Run Responses without Growth Slowdown. See text for description. Authors' Calculations. 


\subsection{The Dynamic System and a Global Slowdown}

The preceding results account for the negative correlation between U.S. financial assets and commodity prices that emerged in the first phase the U.S. financial crisis. Starting in July 2008, however, commodity prices retreated dramatically. Bad news for commodities was also bad news for U.S. and world financial markets.

Of course, this global collapse has many causes and a host of overshooting mechanisms are at work, from balance sheet multipliers, to margin calls, to Knightian Uncertainty that contribute to the overall process of deleveraging. Our framework is not suited to address the role of each these factors. Instead, we emphasize here the dramatic impact of a global economic slowdown. To do so, we re-calibrate our model assuming that a moderate economic slowdown -from $3 \%$ to $2 \%$ annual output growth- takes place unexpectedly one year after the beginning of the U.S. financial crisis.

This moderate decline in global growth is sufficiently large to ensure that assumption 2 is satisfied, so that the global asset market tightness is removed. Figure 15 presents the results. In each panel, the solid line reports the simulation with growth slowdown while the dashed line reports the simulation from figure 14, without a growth slowdown. The collapse in global growth $t=1$, has dramatic consequences on asset and commodity prices. First, lower growth reduces asset values. In the short run, however, it leads to an even larger decline in asset demand. The result is an increase in interest rates (panel A) and a decline in asset prices (panel F). ${ }^{51}$ This decline in asset demand arises from the sudden decline in commodity prices (panel B) that makes commodity producers poorer. As discussed previously, this collapse in commodity prices arises from a downward adjustment in the sustainable long run equilibrium inventories (panel C). The growth slowdown eliminates the dynamic inefficiency of the economy and thus the need to hold inventories in the long run. Inventory holders immediately reduce the rate of accumulation of inventories, which leads to a collapse in the price of commodities. As before, the decline in commodity prices is reinforced by the short run increase in interest rates that makes commodity accumulation less profitable.

The impact on external imbalances is also interesting. While the previous discussion indicated that external imbalances could increase or decrease when growth slows down, we find that for these parameter values, the decline in commodity prices accelerates the process of global rebalancing (panel D), largely through an improvement in the commodity

\footnotetext{
${ }^{51}$ Panel $\mathrm{F}$ reports the total value of $U$ assets - including the bubble for $t \leq 0$ - in the case with (solid line) and without (dashed line) growth slowdown. It also reports the value of the good $U$ asset in the case with growth slowdown (dot-dashed line).
} 
component of the trade balance (panel E).

The growth slowdown generates a pattern of positive comovements for asset prices and commodities that closely matches what the world economy experienced since July 2008. In our framework, the decline in global economic growth reduces the size or even eliminates the bubble by reducing global asset demand. However, it is important to consider here that this experiment assumes that the growth slowdown is permanent, a situation that is highly unlikely. Once real economic conditions recover, our model predicts that asset demand will rise back, recreating the chronic shortage of assets, and the cycle will start again...

\section{Inventories, Oil Prices, and Asset Supply: Some Ev- idence}

\section{$5.1 \quad$ Inventories}

One objection to stories like ours, where asset-demand for oil plays an important role in price determination, is that measured oil inventory levels did not rise during the recent price spike. OECD petroleum inventories increased from 3743 million barrels (mb) in 2000 to $4082 \mathrm{mb}$ in 2008. Yet, this increase mostly occurred between 2000 and 2006. After the onset of the subprime crisis, OECD petroleum inventories declined from $4248 \mathrm{mb}$ to $4082 \mathrm{mb}$ across the board. ${ }^{52}$

Yet, there are at least two reasons why the absence of a rise in measured inventories need not be a serious concern. First, observed inventories are the result of two opposing forces: the asset-market force which leads to an increase in inventories and a demand force which does the opposite. In Appendix D we show that if the long-run elasticity of substitution exceeds one, then inventories follow a non-monotonic path - rising first and declining afterwardsin response to speculation.

Second, as argued by Frankel (2006) and others, producers are the most efficient inventory-

\footnotetext{
${ }^{52}$ In the US, petroleum and crude oil stocks increased between 2000 and 2006 by $307 \mathrm{mb}$ and $168 \mathrm{mb}$ respectively. Since 2007 , US petroleum stocks declined from $1785 \mathrm{mb}$ to $1665 \mathrm{mb}$, while crude oil inventories remained constant at $1020 \mathrm{mb}$. A closer look, however, reveals that non-strategic crude oil inventories decreased by $20 \mathrm{mb}$. The only component of US petroleum stocks that increased since 2006 is the Strategic Petroleum Reserve (SPR) (See Energy Information Administration, Monthly Energy Review, Tables 3.4 and 11.3.). This change in the SPR is a consequence of the Energy Policy Act of 2005, mandating a gradual increase of the SPR from $700 \mathrm{mb}$ to $1000 \mathrm{mb}$. In May 2008, in response to the rapid increase in oil prices, Congress voted to stop depositing oil in the SPR.
} 

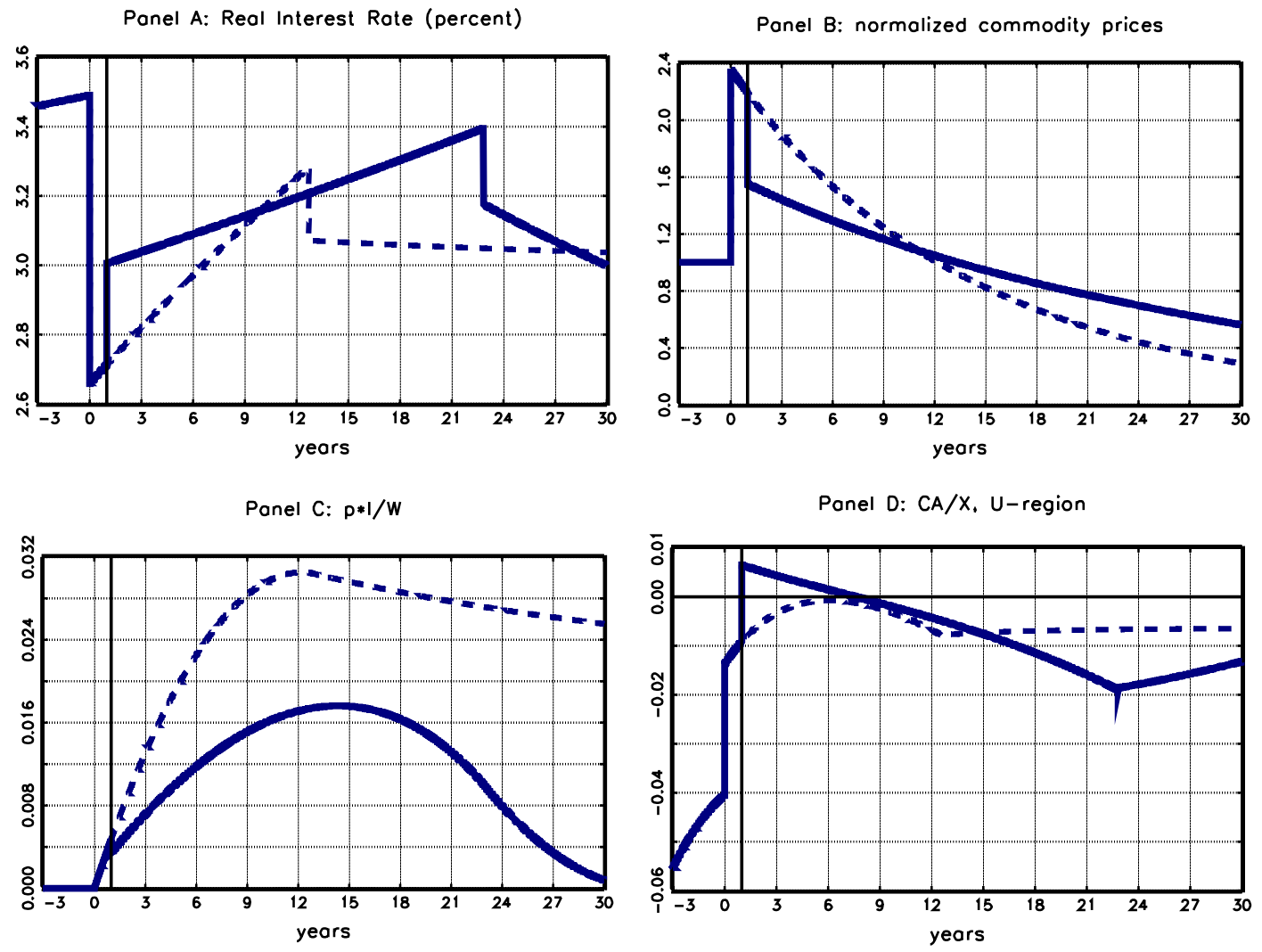

Panel E: Decomposition of TB/X, U-region

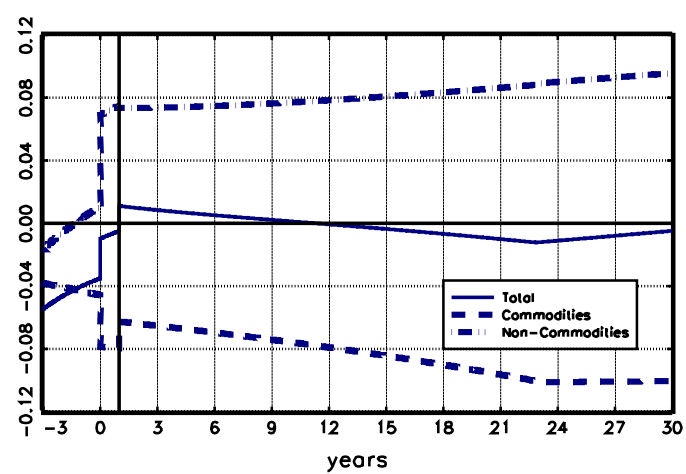

Ponel F: US Financial Assets/Output

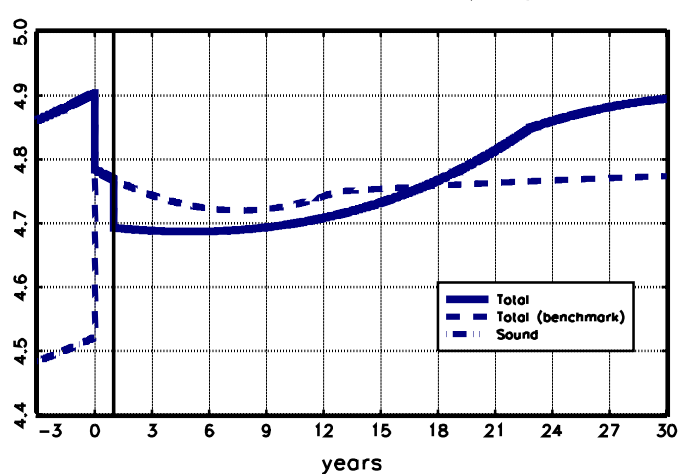

Figure 15: The Dynamic Consequences of the U.S. Subprime Crisis Followed by a Global Growth Slowdown. See text for description. Authors' Calculations. 
holders since they do not need to extract the oil to do so. In our model this amounts to assuming $d^{\text {oilproducer }}<d$, which implies that all inventories are held underground.

Our model is amenable to several interpretations where inventories are just oil in the ground. Suppose, for example, that new reserves of the $Z-$ good are discovered every period. More precisely, the stock of discovered reserves increases by $Z$ per unit of time. The economy cannot consume resources that have not been discovered yet. In addition, suppose that the rights to these new reserves are not capitalized, either because they accrue to new entrants, because they are likely to be expropriated, or because they embody unmodelled uncertainty. This economy would be exactly equivalent to our economy. Under this interpretation, there are no physical inventories of $Z$ - goods. Inventories just reflect discovered and not yet consumed reserves of the $Z$-good.

Another, more abstract, interpretation is that of a social contract in $M$ countries. This (implicit) contract specifies that each generation is entitled to an endowment $Z$ of $Z$-goods. They can decide when to sell it. If they do not sell it immediately, they can store it. Moreover, they can trade rights to future consumption claims on their endowment, that is they can sell the $Z$-good forward. They can also acquire the $Z$ good from agents of the same or different generation in $M$ : they can then treat these newly acquired goods exactly as their own endowment. This economy is once again completely isomorphic to our economy. Inventories are just goods in the ground.

As we show in Appendix C, the underground inventory holding view has important implications for the effectiveness of recent proposals to tax speculative transactions in commodities.

\subsection{The Empirical Link Between Oil Prices and Asset Supply}

The asset-role of oil suggests a negative correlation between oil prices and the value of assets negatively affected by financial shocks, and a positive correlation between oil prices and economic growth. As a starting point we run the simple OLS regression:

$$
\Delta p_{t}=\alpha+\beta \Delta s_{t}+\gamma \Delta y_{t}+\epsilon_{t}
$$

where lower case variables are in log, $p_{t}$ denotes the spot price of crude oil, $s_{t}$ is the Standard \& Poors 500 index and $y_{t}$ is the monthly U.S. Industrial Production index. In the model, a decline in the value of bubble assets that lowers stock prices leads to a reallocation towards 
commodities, so we expect to find $\beta<0$. A decline in growth should also push down commodity prices, so we expect $\gamma>0$. Table 9 reports the results of the simple OLS regression in (23) for the period January 1984 to November 2008. We find a negative but non-significant link between oil prices and stock market performance, and a positive and mostly insignificant link between growth and oil prices.

There are two obvious issues with the OLS regression. First, as shown in figure 8, the apparent correlation is strongly negative only in the first phase of the crisis. In the second phase of the crisis, as explained above, the collapse in global growth reduces both asset and commodity prices. Second, there is an obvious reverse causality concern. For instance, an exogenous increase in oil prices could increase the chance of a recession, leading to a decline in stock returns, or push up inflation rates, leading to a tightening of monetary policy, that would also send equities tumbling. To control for this, we use two instruments: the price of gold, as well as the performance of financial stocks relative to the broader market. Increases in the price of gold are often associated with flight to quality episodes. In fact, since gold provides per se little services or yield, it is the perfect example of an asset held for speculative reasons. The relative performance of financials captures the fact that financial crises impact more directly the financial sector, while there is no reason for oil shocks to affect this service sector more than, e.g. energy-intensive transportation or manufacturing sectors.

The top panel of Table 10 presents the IV estimates. We notice that the coefficient on equities is both much larger, and also strongly significant at the daily, weekly, monthly and quarterly frequencies. The elasticity is always in excess of one. The coefficient on growth has the correct sign at the quarterly and annual frequency, but appears to be insignificant. The bottom panel reports the first stage of the IV regression.

Financial relative performance has the right impact on equilibrium assets values at all frequencies but annual: conditional on growth, bad news in U.S. financial markets is good news for oil as an asset. Conversely, good news in U.S. financial markets is bad news for oil. $^{53}$

\footnotetext{
${ }^{53}$ The results are similar if we restrict the sample to the period before July 2008, preceding the second phase of the crisis.
} 


\begin{tabular}{lcccccccccc}
\hline & $\begin{array}{c}(1) \\
\text { daily }\end{array}$ & $\begin{array}{c}(2) \\
\text { weekly }\end{array}$ & $\begin{array}{c}(3) \\
\text { monthly }\end{array}$ & $\begin{array}{c}(4) \\
\text { quarterly }\end{array}$ & $\begin{array}{c}(5) \\
\text { annual }\end{array}$ & $\begin{array}{c}(6) \\
\text { daily }\end{array}$ & $\begin{array}{c}(7) \\
\text { weekly }\end{array}$ & $\begin{array}{c}(8) \\
\text { monthly }\end{array}$ & $\begin{array}{c}(9) \\
\text { quarterly }\end{array}$ & $\begin{array}{c}(10) \\
\text { annual }\end{array}$ \\
\hline SP500 & -0.06 & -0.01 & -0.07 & -0.45 & -0.44 & -0.06 & -0.02 & -0.11 & -0.50 & -0.63 \\
& $(1.41)$ & $(0.13)$ & $(0.37)$ & $(1.59)$ & $(1.42)$ & $(1.39)$ & $(0.17)$ & $(0.72)$ & $(1.73)$ & $(2.57)$ \\
Ind. Prod. & & & 1.30 & 3.10 & 1.81 & & & 1.03 & 2.23 & -0.59 \\
& & & $(1.25)$ & $(2.04)$ & $(1.23)$ & & & $(1.05)$ & $(1.11)$ & $(0.27)$ \\
Lagged: & & & & & & & & & & \\
SP500 & & & & & & 0.06 & -0.07 & -0.07 & 0.67 & 0.22 \\
& & & & & & $(1.58)$ & $(0.83)$ & $(0.43)$ & $(0.29)$ & $(0.67)$ \\
Ind. Prod. & & & & & & & & 2.68 & 1.07 & 2.43 \\
& & & & & & & & $(2.02)$ & $(0.57)$ & $(0.97)$ \\
Observations & 6233 & 1296 & 297 & 295 & 286 & 6232 & 1295 & 296 & 294 & 285 \\
R-squared & 0.000 & 0.000 & 0.001 & & & 0.001 & 0.001 & 0.04 & & \\
\hline
\end{tabular}

Table 9: Oil-Stock Market Regressions.Sample period is 1/1/1984-11/8/2008. Dependent variable is change in log of the spot price of crude; independent variables are change in log S\&P 500 and change in industrial production index. Changes are taken over the end-of-period value for each interval. Quarterly and annual regressions are run on overlapping monthly data. Eicker-White robust t-statistics are reported in parentheses for the daily, weekly and monthly regressions; Newey-West t-statistics are reported for the quarterly and annual regressions, with windows of 2 and 11 months, respectively. Constant included in the regression and not reported

\begin{tabular}{|c|c|c|c|c|c|}
\hline & $\begin{array}{c}(1) \\
\text { daily }\end{array}$ & $\begin{array}{c}(2) \\
\text { weekly }\end{array}$ & $\begin{array}{c}(3) \\
\text { monthly }\end{array}$ & $\begin{array}{c}(4) \\
\text { quarterly }\end{array}$ & $\begin{array}{c}5) \\
\text { annual }\end{array}$ \\
\hline SP500 & $\begin{array}{l}-1.14 \\
(4.95)\end{array}$ & $\begin{array}{l}-1.52 \\
(3.45)\end{array}$ & $\begin{array}{l}-2.96 \\
(3.12)\end{array}$ & $\begin{array}{l}-3.08 \\
(3.71)\end{array}$ & $\begin{array}{c}-3.74 \\
(1.98)\end{array}$ \\
\hline Ind. Prod. & & & $\begin{array}{l}-0.94 \\
(0.40)\end{array}$ & $\begin{array}{c}3.86 \\
(1.25)\end{array}$ & $\begin{array}{c}7.99 \\
(1.39)\end{array}$ \\
\hline \multicolumn{6}{|c|}{ First Stage regressions (dependent variable SEP 500) } \\
\hline Financials & $\begin{array}{c}0.29 \\
(8.55)\end{array}$ & $\begin{array}{c}0.28 \\
(5.56)\end{array}$ & $\begin{array}{c}0.29 \\
(2.96)\end{array}$ & $\begin{array}{c}0.29 \\
(2.75)\end{array}$ & $\begin{array}{l}-0.01 \\
(0.06)\end{array}$ \\
\hline gold & $\begin{array}{l}-0.11 \\
(3.87)\end{array}$ & $\begin{array}{l}-0.08 \\
(1.91)\end{array}$ & $\begin{array}{l}-0.09 \\
(0.94)\end{array}$ & $\begin{array}{c}-0.11 \\
(1.21)\end{array}$ & $\begin{array}{c}-0.28 \\
(1.83)\end{array}$ \\
\hline R-squared & 0.06 & 0.06 & 0.06 & & \\
\hline Observations & 6098 & 1296 & 297 & 295 & 286 \\
\hline
\end{tabular}

Table 10: Instrumented Oil-Stock Market Regressions. Sample period is 1984-2008. Dependent variable is change in log of the spot price of crude; independent variables are change in log S\&P 500 and change in Industrial Production Index. Instruments are the log change in the price of S\&P 500 financials less the S\&P 500 , and the log change in the price of gold. Changes are taken over the end-of-period value for each interval. Quarterly and annual regressions are run on overlapping monthly data. Eicker-White robust t-statistics are reported in parentheses for the daily, weekly and monthly regressions; Newey-West t-statistics are reported for the quarterly and annual regressions, with windows of 2 and 11 months, respectively. Constant included in the regression and not reported. 


\section{Final Discussion}

The prevailing view is one of central banks excesses and mistakes leading to excess liquidity, speculative bubbles, and unavoidable crises. This seems overstated: central banks, when reasonable, are not nearly as powerful. In this paper we take a contrarian view and provide an entirely private-sector account of the main facts, without any role for monetary factors. Reality is probably in between.

Our framework builds on the idea that the world economy entered the crisis with a chronic excess demand for financial assets, where the subprime market development may just have been a (failed) market attempt to bridge this gap. Within this perspective, we argue that the sharp rise in oil prices following the subprime crisis - nearly 100 percent in just a matter of months and on the face of recessionary shocks - was the result of a speculative response to the financial crisis itself, in an attempt to rebuild asset supply. That is, the global economy was subject to one shock with multiple implications rather than to two separate shocks (financial and oil).

Eventually, the persistent financial crisis and its many multipliers severely hurt growth prospects, which triggered and implosion in commodity prices and asset demand more broadly. However, by the same token, when real conditions recover, our model predicts that asset demand is likely to rise back, recreating the chronic shortage of assets, and the cycle will start again. Regulation, unless distortionary enough to depress growth, is no match for these market forces. The real problem is more macroeconomic in nature and unlikely to go away until the world economy's ability to generate sound store of value catches up with its potential income growth. That is, as so much else on these days, it depends largely on developments within China and other emerging markets. 


\section{References}

Beltran, Daniel O., Laurie Pounder, and Charles Thomas, "Foreign Exposure to Asset-Backed Securities of U.S. Origin," International Finance Discussion Papers 939, Board of Governors of the Federal Reserve System (U.S.) 2008.

Bernanke, Ben, "The Global Saving Glut and the U.S. Current Account Deficit," Sandridge Lecture, Virginia Association of Economics, Richmond, Virginia, Federal Reserve Board March 2005.

Blanchard, Olivier, Francesco Giavazzi, and Filipa Sa, "International Investors, the U.S. Current Account, and the Dollar," in "Brookings Papers on Economic Activity" Spring 2005, pp. 1-65.

Brunnermeier, Markus K., "Deciphering the 2007-08 Liduidity and Credit Crunch," Journal of Economic Perspectives, forthcoming 2008.

Caballero, Ricardo J. and Arvind Krishnamurthy, "Bubbles and Capital Flow Volatility: Causes and Risk Management," Journal of Monetary Economics, January 2006, 53:1.

_, Emmanuel Farhi, and Pierre-Olivier Gourinchas, "An Equilibrium Model of "Global Imbalances" and Low Interest Rates," American Economic Review, March 2008, $98(1), 358-93$.

Dahl, Carol and Thomas Sterner, "Analysing gasoline demand elasticities: a survey," Energy Economics, July 1991, 13 (3), 203-210.

Deutsche Bank, "Sovereign Wealth Funds - State Investments on the Rise," Current Issues September 2007.

Frankel, Jeffrey A., "The Effect of Monetary Policy on Real Commodity Prices," NBER Working Papers 12713 December 2006.

Gately, Dermot and Hillard G. Huntington, "The Asymmetric Effects of Changes in Price and Income on Energy and Oil Demand," Energy Journal, 2002, 23 (1), 19-56.

Greenlaw, David, Jan Hatzius, Anil K Kashyap, and Hyun Song Shin, "Leveraged Losses: Lessons from the Mortgage Market Meltdown," U.S. Monetary Policy Forum Report No. 22008. 
Hamilton, James, "Understanding Crude Oil Prices," mimeo, UC San Diego May 2008.

Hotelling, Harold, "The Economics of Exhaustible Resources," Journal of Political Economy, August 1931, 39 (2), 137-175.

Hughes, Jonathan E., Christopher R. Knittel, and Daniel Sperling, "Evidence of a Shift in the Short-Run Price Elasticity of Gasoline Demand," Energy Economics, 2008, $29(1), 93-114$.

IMF, Containing Systemic Risk and Restoring Financial Soundness: Global Financial Stability Report, International Monetary Fund, April 2008.

_, Financial Stress and Deleveraging: Global Financial Stability Report, International Monetary Fund, October 2008.

Jovanovic, Boyan, "Bubbles in Prices of Exhaustible Resources," NBER Working Papers 13320 August 2007.

Kouri, Pentti, "Balance of Payment and the Foreign Exchange Market: A Dynamic Partial Equilibrium Model," in Jagdeep Bhandari and Bluford Putnam, eds., Economic Interdependance and Flexible Exchange Rates, MIT Press, 1982, pp. 116-156.

Metzler, Lloyd A., "The process of International Adjustment under Conditions of Full Employment. A Keynesian View," in Richard Caves and Harry G. Johnson, eds., Readings in International Economics, Richard D. Irwin, Homewood, IL 1960, pp. 465-486.

Milesi-Ferretti, Gian Maria, "Fundamentals at Odds? The Dollar and The U.S. Current Account Deficit," mimeo prepared for the June 27-28 Siena conference on The Impact of Global Imbalances September 2008.

Nordhaus, William D, "Oil and Economic Performance in Industrial Countries," Brookings Papers on Economic Activity, 1980, 1980 (2), 341-399.

Roy, Joyashree, Alan H. Sanstad, Jayant A. Sathaye, and Raman Khaddaria, "Substitution and price elasticity estimates using inter-country pooled data in a translog cost model," Energy Economics, November 2006, 28 (5-6), 706-719.

Sercu, Piet M. and Rosanne Vanpee, "Home Bias in International Equity Portfolios: A Review," KU Leuven mimeo 2007. 


\section{Appendix A}

\section{Derivations for Sections 2 and 3}

\section{A.1 Asset Decline and Trade Balance when $\sigma<1$ : the petrodol- lar effect}

In this section, we provide the analysis underlying the claims in Sections 3.1 and 3.2 regarding the case where the elasticity of substitution $\sigma$ between $X$ and $Z$ is less than one. Formally, recall that in equilibrium $\theta W_{t}=\left(1+\alpha p_{t}^{1-\sigma}\right) X_{t}$. Because $I_{t_{0}}=0, W_{t_{0}^{+}}=V_{t_{0}^{+}}$and therefore $V_{t_{0}^{+}}-\left(V_{t_{0}^{-}}+B_{t_{0}^{-}}\right)>0$ when $\sigma<1$. This increase in global asset value (when measured in units of $X)$ mitigates the fall in the value of $U$-assets. In fact the change in wealth can be expressed as

$$
B_{t_{0}^{-}}+V_{t_{0}^{-}}^{U}-V_{t_{0}^{+}}^{U}=B_{t_{0^{-}}}\left(1-x_{t_{0}}^{U}\right)-\frac{\alpha}{\theta} X_{t_{0}}^{U}\left(p_{t_{0}^{+}}^{1-\sigma}-p_{t_{0}^{-}}^{1-\sigma}\right) .
$$

The first term on the right hand side of this expression is positive and is exactly the same as in equation (20). It represents the direct effect of the bubble-burst and also corresponds to the drop in $U^{\prime} s$ wealth that would occur in the benchmark no-inventory economy. The second term is negative in our economy but vanishes in the benchmark no-inventory economy. It represents the drop in the share of the $X$ good in total consumption, and mitigates the fall in the value of $U$ 's assets. As we argued earlier, this "petrodollar" term plays a key role in limiting the extent of short-run rebalancing.

Consider now the impact effects of the growth slowdown shock. We maintain the assumption of extreme home bias so that immediately before the growth slowdown shock hits, all of $U$ 's wealth is invested in $U$ assets. The adjustment in the trade balance is always positive:

$$
T B_{t_{1}^{+}}^{U}-T B_{t_{1}^{-}}^{U}=-\theta\left(W_{t_{1}^{+}}^{U}-W_{t_{1}^{-}}^{U}\right)=\theta \mu_{t_{1^{-}}}\left(V_{t_{1}^{-}}^{U}-V_{t_{1}^{+}}^{U}\right)
$$

where $\mu_{t_{1-}}=W_{t_{1}^{-}}^{U} /\left(V_{t_{1}^{-}}^{U}+B_{t_{1-}}\right)$. The change in the value of $U$ assets can be computed as above

$$
V_{t_{1}^{+}}^{U}-V_{t_{1}^{-}}^{U}=x_{t_{1}}^{U} \frac{\alpha}{\theta}\left(p_{t_{1}^{+}}^{1-\sigma}-p_{t_{1}^{-}}^{1-\sigma}\right) X_{t}-x_{t_{1}}^{U}\left(p_{t_{1}^{+}}-p_{t_{1}^{-}}\right) I_{t_{1}}
$$

The second term is negligible if $I_{t_{1}}$ is small. Since the first term is equal to 0 when $\sigma=1$, we have that in this benchmark the impact of the growth slowdown on the trade balance is negligible. By contrast, when $\sigma<1$, the first term is negative and, under our calibration, it swamps the second term. Thus, the trade balance improves at impact. 


\section{A.2 The Trade Balance in the short Run}

In this section we expand on Section 3.1 and analyze the behavior of the trade balance in the short run both in our economy and in the benchmark no-inventory economy.

We can decompose this difference more finely by studying the trade balance decomposition into exports $X_{t}^{U}-\theta W_{t}^{U} /\left(1+\alpha p_{t}^{1-\sigma}\right)$ and imports $\alpha p_{t}^{1-\sigma} \theta W_{t}^{U} /\left(1+\alpha p_{t}^{1-\sigma}\right)$ :

$$
\begin{aligned}
T B_{t_{0}^{+}}^{U}-T B_{t_{0}^{-}}^{U}= & \left(\frac{\theta W_{t_{0}^{-}}^{U}}{1+\alpha p_{t_{0}^{-}}^{1-\sigma}}-\frac{\theta W_{t_{0}^{+}}^{U}}{1+\alpha p_{t_{0}^{+}}^{1-\sigma}}\right)-p_{t_{0}^{+}}\left(\frac{\alpha p_{t_{0}^{+}}^{-\sigma} \theta W_{t_{0}^{+}}^{U}}{1+\alpha p_{t_{0}^{+}}^{1-\sigma}}-\frac{\alpha p_{t_{0}^{-}}^{-\sigma} \theta W_{t_{0}^{-}}^{U}}{1+\alpha p_{t_{0}^{-}}^{1-\sigma}}\right) \\
& -\left(p_{t_{0}^{+}}-p_{t_{0}^{-}}\right) \frac{\alpha p_{t_{0}^{-}}^{-\sigma} \theta W_{t_{0}^{-}}^{U}}{1+\alpha p_{t_{0}^{-}}^{1-\sigma}}
\end{aligned}
$$

The three terms on the right hand side have a traditional Marshall-Lerner interpretation: The first one represents the increase in the volume of exports. The second one represents the decrease in the volume of imports times the terms of trade. These two are positive since the volume of exports rises and the volume of imports falls. The third term is negative and represents imports times the change in the terms of trade. Note that the terms of trade effect - the last term- would be absent in the benchmark no-inventory economy. However, we can show that the positive quantity effect - the first two terms - is stronger in our economy than in the benchmark economy, which means that the difference in trade rebalancing between these two economies is strictly less than the direct effect of the change in terms of trade resulting from speculation in commodities. ${ }^{54}$

${ }^{54}$ This can be verified as follows. The claim amounts to showing that

$$
\left(p_{t_{0}^{+}}-p_{t_{0}^{-}}\right) \frac{\alpha p_{t_{0}^{-}}^{-\sigma} \theta W_{t_{0}^{-}}^{U}}{1+\alpha p_{t_{0}^{-}}^{1-\sigma}}>\theta \frac{W_{t_{0}^{-}}^{U}}{B_{t_{0}^{-}}+V_{t_{0}^{-}}^{U}} \frac{\alpha}{\theta} X_{t_{0}}^{U}\left(p_{t_{0}^{+}}^{1-\sigma}-p_{t_{0}^{-}}^{1-\sigma}\right)
$$

which can be re-arranged into

$$
\frac{\frac{p_{t_{0}^{+}}}{p_{t_{0}^{-}}}\left(1-\frac{p_{t_{0}^{+}}^{-\sigma}}{p_{t_{0}^{-}}^{-\sigma}}\right)}{\frac{p_{t_{0}^{+}}^{1-\sigma}}{p_{t_{0}^{-}}^{1-\sigma}}-1}+1>\frac{1}{1+\frac{B_{t_{0}^{-}}}{B_{t_{0}^{-}}+V_{t_{0}^{-}}}\left(1-\frac{X_{t_{0}}^{U}}{X_{t}^{0}}\right)} .
$$




\section{A.3 The Commodity-Price-Jump Term}

The drop in interest rates at $t=t_{0}$ when $\sigma<1$ can be expressed as:

$$
\begin{aligned}
r_{t_{0}^{+}}-r_{t_{0}^{-}}= & -g \frac{B_{t_{0}^{-}}}{W_{t_{0}^{-}}} \\
& +\left(\frac{\delta \theta\left(1-s_{z t_{0}^{-}}\right)+\theta\left(\left(\frac{p_{t_{0}}}{p_{t_{0}}}\right)^{1-\sigma}-\frac{p_{t_{0+}}}{p_{t_{0}}}\right) s_{z t_{0}^{-}}}{1+s_{z t_{0}^{-}}\left(\sigma\left(\frac{p_{t_{0+}}}{p_{t_{0}}}\right)^{1-\sigma}-1\right)}\right)-\delta \theta\left(1-s_{z t_{0}^{-}}\right)-\frac{g(1-\sigma)}{\sigma} s_{z t_{0}^{-}}
\end{aligned}
$$

where where $s_{z t}$ is the expenditure share of commodities. The first term on the right hand side represents the 'bubble-burst' term discussed in section 1.3. The second term is the 'commodityprice-jump' term introduced in Section 3.3.

\section{A.4 The Numeraire}

Throughout we have chosen the $X$-good as the numeraire. This section confirms the claim in Section 1.2 that the main substantive results do not depend on this particular choice of numeraire. The price index corresponding to the composite consumption good is given by $\left(1+\alpha p_{t}^{1-\sigma}\right)^{1 /(1-\sigma)}$ if $\sigma \neq 1$, and $p_{t}^{\frac{\alpha}{1+\alpha}}$ if $\sigma=1$. We term the corresponding numeraire the composite numeraire. We denote with a tilde the variable expressed in the composite numeraire. The interest rate in the composite numeraire $\tilde{r}_{t}$ can be computed from $r_{t}$ as follows:

$$
\tilde{r}_{t}=r_{t}-\frac{d \log \left[\left(1+\alpha p_{t}^{1-\sigma}\right)^{1 /(1-\sigma)}\right]}{d t}=r_{t}-\frac{\alpha p_{t}^{-\sigma}}{1+\alpha p_{t}^{1-\sigma}} \dot{p}_{t}
$$

If $\max \left\{I_{t}, \dot{I}_{t}\right\}>0$, we have

$$
\tilde{r}_{t}=r_{t}-\frac{\alpha p_{t}^{-\sigma}\left(r_{t}+d\right) p_{t}}{1+\alpha p_{t}^{1-\sigma}}=\frac{r_{t}-d \alpha p_{t}^{1-\sigma}}{1+\alpha p_{t}^{1-\sigma}}
$$

which using (10) we can rewrite as

$$
\tilde{r}_{t}=\theta \frac{\left(\delta+g \frac{B_{t}+p_{t} I_{t}}{X_{t}}\right)-\left(\frac{p_{t} Z}{X_{t}}-\alpha p_{t}^{1-\sigma}\right)}{\left(1+\alpha \sigma p_{t}^{1-\sigma}\right)\left(1+\alpha p_{t}^{1-\sigma}\right)}+\tilde{\epsilon}_{d}
$$

where $\tilde{\epsilon}_{d}=-\sigma d \alpha p_{t}^{1-\sigma} /\left(1+\alpha \sigma p_{t}^{1-\sigma}\right)$. In the rest of this discussion we consider the limit case $d=0$. Let's now investigate how this change in numeraire would modify our conclusions concerning the 
crash and the steady states. Note that when $\sigma=1$ then we simply have

$$
\tilde{r}_{t}=\frac{r_{t}}{1+\alpha}
$$

Hence

$$
\tilde{r}_{t_{0}^{-}}-\tilde{r}_{t_{0}^{+}}=\frac{r_{t_{0}^{-}}-r_{t_{0}^{+}}}{1+\alpha}=\frac{1}{1+\alpha}\left[\frac{\theta g}{1+\alpha} \frac{\tilde{B}_{t_{0-}}^{U}}{p_{t_{0}^{-}}^{\frac{\alpha}{1+\alpha}} X_{t_{0}}}+\frac{\theta}{1+\alpha} \frac{Z}{X_{t_{0}}}\left(p_{t_{0}^{+}}-p_{t_{0}^{-}}\right)\right] .
$$

Let's now turn to the drop in wealth and asset value at impact. We have

$$
\begin{aligned}
& \frac{\theta \tilde{W}_{t_{0}^{-}}}{1+\alpha}=p_{t_{0}^{-}}^{-\frac{\alpha}{1+\alpha}} X_{t_{0}}=\tilde{V}_{t_{0}^{-}}^{U} \frac{X_{t_{0}}}{X_{t_{0}}^{U}}+\tilde{B}_{t_{0}-}^{U} \\
& \frac{\theta \tilde{W}_{t_{0}^{+}}}{1+\alpha}=p_{t_{0}^{+}}^{-\frac{\alpha}{1+\alpha}} X_{t_{0}}=\tilde{V}_{t_{0}^{+}}^{U} \frac{X_{t_{0}}}{X_{t_{0}}^{U}}
\end{aligned}
$$

Hence we obtain

$$
\tilde{V}_{t_{0}^{-}}^{U}+\tilde{B}_{t_{0^{-}}}^{U}-\tilde{V}_{t_{0}^{+}}^{U}=\tilde{B}_{t_{0-}}^{U}\left(1-\frac{X_{t_{0}}^{U}}{X_{t_{0}}}\right)+\left(p_{t_{0}^{-}}^{-\frac{\alpha}{1+\alpha}}-p_{t_{0}^{+}}^{-\frac{\alpha}{1+\alpha}}\right) \frac{1}{\theta} X_{t_{0}}^{U}
$$

The amount of rebalancing is given by $\widetilde{C A}_{t_{0}^{+}}^{U}-\widetilde{C A}_{t_{0}^{-}}^{U}$

$$
\begin{aligned}
& {\left[\tilde{r}_{t_{0}^{-}}\left(1-\frac{\tilde{W}_{t_{0}^{-}}^{U}}{\tilde{V}_{t_{0}^{-}}^{U}+\tilde{B}_{t_{0}-}^{U}}\right)+\theta \frac{\tilde{W}_{t_{0}^{-}}^{U}}{\tilde{V}_{t_{0}^{-}}^{U}+\tilde{B}_{t_{0}-}^{U}}\right]\left(\tilde{V}_{t_{0}^{-}}^{U}+\tilde{B}_{t_{0}-}^{U}-\tilde{V}_{t_{0}^{+}}^{U}\right)-X_{t_{0}}^{U} \frac{1}{\theta}\left(p_{t_{0}^{-}}^{-\frac{\alpha}{1+\alpha}}-p_{t_{0}^{+}}^{-\frac{\alpha}{1+\alpha}}\right)} \\
& +\left(\tilde{r}_{t_{0}^{-}}-\tilde{r}_{t_{0}^{+}}\right)\left(\tilde{V}_{t_{0}^{-}}^{U}+\tilde{B}_{t_{0-}}^{U}-\tilde{W}_{t_{0}^{-}}^{U}\right) \frac{\tilde{V}_{t_{0}^{+}}^{U}}{\tilde{V}_{t_{0}^{-}}^{U}+\tilde{B}_{t_{0}-}^{U}}
\end{aligned}
$$

The right comparison when we use the composite numeraire should be with an economy with exogenous commodity prices. With endogenous commodity prices, the interest rate drops more. The drop in asset value is also more pronounced because the trees pay dividend in $X$-goods the value of which depreciates at impact. Both effects contribute to more rebalancing with endogenous commodity prices. A counterbalancing effect is that the value of GDP goes down since GDP is composed of $\mathrm{X}$ goods, the value of which depreciates at impact. This last effect contributes to less rebalancing.

Another quantity we could look at is the amount of rebalancing as a fraction of GDP $\widetilde{C A} t_{t_{0}^{+}}^{U} /\left(p_{t_{0}^{+}}^{-\frac{\alpha}{1+\alpha}} X_{t_{0}}^{U}\right)-$ 


$$
\begin{aligned}
& \widetilde{C A}_{t_{0}^{-}}^{U} /\left(p_{t_{0}^{-}}^{-\frac{\alpha}{1+\alpha}} X_{t_{0}}^{U}\right) \\
& {\left[\tilde{r}_{t_{0}^{-}}\left(1-\frac{\tilde{W}_{t_{0}^{-}}^{U}}{\tilde{V}_{t_{0}^{-}}^{U}+\tilde{B}_{t_{0}}^{U}}\right)+\theta \frac{\tilde{W}_{t_{0}^{-}}^{U}}{\tilde{V}_{t_{0}^{-}}^{U}+\tilde{B}_{t_{0}-}^{U}}\right]\left(\frac{\tilde{V}_{t_{0}^{-}}^{U}+\tilde{B}_{t_{0}}^{U}}{p_{t_{0}^{-}}^{-\frac{\alpha}{1+\alpha}} X_{t_{0}}^{U}}-\frac{\tilde{V}_{t_{0}^{+}}^{U}}{p_{t_{0}^{+}}^{-\frac{\alpha}{1+\alpha}} X_{t_{0}}^{U}}\right) } \\
&+\left(\tilde{r}_{t_{0}^{-}}-\tilde{r}_{t_{0}^{+}}\right) \frac{\tilde{V}_{t_{0}^{-}}^{U}+\tilde{B}_{t_{0}-}^{U}-\tilde{W}_{t_{0}^{-}}^{U}}{p_{t_{0}^{-}}^{-\frac{\alpha}{1+\alpha}} X_{t_{0}}^{U}} \frac{\tilde{V}_{t_{0}^{+}}^{U}}{\tilde{V}_{t_{0}^{-}}^{U}+\tilde{B}_{t_{0}-}^{U}} \frac{p_{t_{0}^{-}}^{-\frac{\alpha}{1+\alpha}}}{p_{t_{0}^{+}}^{\frac{\alpha}{1+\alpha}}}
\end{aligned}
$$

which we can rewrite as

$$
\begin{aligned}
& {\left[\tilde{r}_{t_{0}^{-}}\left(1-\frac{\tilde{W}_{t_{0}^{-}}^{U}}{\tilde{V}_{t_{0}^{-}}^{U}+\tilde{B}_{t_{0}}^{U}}\right)+\theta \frac{\tilde{W}_{t_{0}^{-}}^{U}}{\tilde{V}_{t_{0}^{-}}^{U}+\tilde{B}_{t_{0}-}^{U}}\right] \frac{B_{t_{0}-}^{U}}{X_{t_{0}}^{U}}\left(1-\frac{X_{t_{0}}^{U}}{X_{t_{0}}}\right)} \\
& +\left(\tilde{r}_{t_{0}^{-}}-\tilde{r}_{t_{0}^{+}}\right)\left(\tilde{V}_{t_{0}^{-}}^{U}+\tilde{B}_{t_{0^{-}}}^{U}-\tilde{W}_{t_{0}^{-}}^{U}\right) \frac{V_{t_{0}^{+}}^{U}}{V_{t_{0}^{-}}^{U}+B_{t_{0^{-}}}^{U}}
\end{aligned}
$$

With this normalization, endogenous commodity prices only contribute to less rebalancing with $\sigma=1$ because they lead to lower interest rates.

Let's now turn to $\sigma<1$. In this case we have $\tilde{r}_{t}=\frac{r_{t}}{1+\alpha p_{t}^{1-\sigma}}$ so that

$$
\tilde{r}_{t_{0}^{-}}-\tilde{r}_{t_{0}^{+}}=\frac{r_{t_{0}^{-}}-r_{t_{0}^{+}}}{1+\alpha p_{t_{0}^{-}}^{1-\sigma}}+r_{t_{0}^{+}}\left(\frac{1}{1+\alpha p_{t_{0}^{-}}^{1-\sigma}}-\frac{1}{1+\alpha p_{t_{0}^{+}}^{1-\sigma}}\right)
$$

Similarly, we have

$$
\frac{\tilde{V}_{t_{0}^{-}}^{U}+\tilde{B}_{t_{0}-}^{U}}{\left(1+\alpha p_{t_{0}^{-}}^{1-\sigma}\right)^{-1 /(1-\sigma)} X_{t_{0}}^{U}}-\frac{\tilde{V}_{t_{0}^{+}}^{U}}{\left(1+\alpha p_{t_{0}^{+}}^{1-\sigma}\right)^{-1 /(1-\sigma)} X_{t_{0}}^{U}}=\frac{B_{t_{0}-}^{U}}{X_{t_{0}}^{U}}\left(1-\frac{X_{t_{0}}^{U}}{X_{t_{0}}}\right)-\alpha \frac{1}{\theta}\left(p_{t_{0}^{+}}^{1-\sigma}-p_{t_{0}^{-}}^{1-\sigma}\right) .
$$

And we can compute $\widetilde{C A} t_{0}^{+} /\left(\left(1+\alpha p_{t_{0}^{+}}^{1-\sigma}\right)^{-1 /(1-\sigma)} X_{t_{0}}^{U}\right)-\widetilde{C A}_{t_{0}^{-}}^{U} /\left(\left(1+\alpha p_{t_{0}^{-}}^{1-\sigma}\right)^{-1 /(1-\sigma)} X_{t_{0}}^{U}\right)$

$$
\begin{aligned}
& {\left[\tilde{r}_{t_{0}^{-}}\left(1-\frac{\tilde{W}_{t_{0}^{-}}^{U}}{\tilde{V}_{t_{0}^{-}}^{U}+\tilde{B}_{t_{0}-}^{U}}\right)+\theta \frac{\tilde{W}_{t_{0}^{-}}^{U}}{\tilde{V}_{t_{0}^{-}}^{U}+\tilde{B}_{t_{0}}^{U}}\right]\left(\frac{\tilde{V}_{t_{0}^{-}}^{U}+\tilde{B}_{t_{0}-}^{U}}{\left(1+\alpha p_{t_{0}^{-}}^{1-\sigma}\right)^{-1 /(1-\sigma)} X_{t_{0}}^{U}}-\frac{\tilde{V}_{t_{0}^{+}}^{U}}{\left(1+\alpha p_{t_{0}^{+}}^{1-\sigma}\right)^{-1 /(1-\sigma)} X_{t_{0}}^{U}}\right)} \\
& +\left(\tilde{r}_{t_{0}^{-}}-\tilde{r}_{t_{0}^{+}}\right)\left(\frac{\tilde{V}_{t_{0}^{-}}^{U}+\tilde{B}_{t_{0}-}^{U}-\tilde{W}_{t_{0}^{-}}^{U}}{\left(1+\alpha p_{t_{0}^{-}}^{1-\sigma}\right)^{-1 /(1-\sigma)} X_{t_{0}}^{U}}\right) \frac{\tilde{V}_{t_{0}^{+}}^{U}}{\tilde{V}_{t_{0}^{-}}^{U}+\tilde{B}_{t_{0}-}^{U}} \frac{\left(1+\alpha p_{t_{0}^{-}}^{1-\sigma}\right)^{-1 /(1-\sigma)}}{\left(1+\alpha p_{t_{0}^{+}}^{1-\sigma}\right)^{-1 /(1-\sigma)}}
\end{aligned}
$$


Hence when net positions are small compared to gross positions endogenous commodity prices can lead to less rebalancing. All the qualitative conclusions of the paper remain unchanged.

\section{Appendix B}

\section{Derivations for Section 4}

In this appendix, we provide the analysis underlying the calibration and the dynamic system in Section 4.

\section{B.1 The bubble economy: $t<t_{0}$.}

We start the economy in the bubble equilibrium with $\sigma<1$, for $t<t_{0}$. The economy is characterized by the following equations:

$$
\begin{aligned}
\dot{B}_{t} & =r_{t} B_{t} \\
r_{t} & =\frac{\delta \theta+\theta g B_{t} / X_{t}+\alpha \hat{q}^{1-\sigma} X_{t}^{1 / \sigma-1} g(1 / \sigma-1)}{1+\alpha \hat{q}^{1-\sigma} X_{t}^{1 / \sigma-1}}
\end{aligned}
$$

where $\hat{q} \equiv p_{t} / X_{t}^{1 / \sigma}=(\alpha / Z)^{1 / \sigma}$ is constant. This is a differential system in $B_{t}$ with a forcing term $X_{t}$. It requires a terminal condition. To find this terminal condition, we need to characterize the path of the economy, in the event that the bubble does not collapse. Observe that $p_{t}=\hat{q} X_{t}^{1 / \sigma}$, hence the share of consumption expenditures on the $Z$-good, $s_{z t}=\alpha p_{t}^{1-\sigma} /\left(1+\alpha p_{t}^{1-\sigma}\right)$, is increasing without bounds. The transition to $\sigma=1$ must occur at some time $T_{1}$ such that $\alpha \hat{q}^{1-\sigma} X_{T_{1}}^{1 / \sigma-1}=\alpha^{\prime}$. From $T_{1}$ onwards, the elasticity of substitution is equal to one. The bubble economy with $\sigma=1$ reaches its steady state instantly with:

$$
\begin{aligned}
r_{t} & =g ; \quad q_{t}=\alpha^{\prime} / Z \\
\frac{W_{t}}{X_{t}} & =\frac{1+\alpha^{\prime}}{\theta} ; \quad \frac{V_{t}}{X_{t}}=\frac{V_{t}^{U}}{X_{t}^{U}}=\frac{\delta}{g} \\
B_{t} & =\left[\frac{1+\alpha^{\prime}}{\theta}-\frac{\delta}{g}\right] X_{t}
\end{aligned}
$$

This provides the terminal condition for the value of the bubble at time $T_{1^{-}}: B_{T_{1-}}=\left[\frac{\left(1+\alpha^{\prime}\right)}{\theta}-\frac{\delta}{g}\right] X_{T_{1}}$. Solving backwards from $t=T_{1}$, we can then characterize the entire path $\left\{B_{t}, W_{t}, V_{t}, V_{t}^{U}, p_{t}\right\}$ that is expected to occur in the absence of a collapse of the bubble.

This global system is consistent with any initial net foreign asset position at $t=t_{0}$. Assume that we want to start the economy with an external debt $N A_{t_{0}}^{U}=\eta X_{t_{0}}^{U}$. Under the assumption that the 
bubble is initially located in $U$, this implies that $U$ 's savings are equal to $W_{t_{0}}^{U}=V_{t_{0}}^{U}+B_{t_{0}}+\eta X_{t_{0}}^{U}$. One can then solve for the path of domestic savings from the asset accumulation equation. In turn, this pins down net foreign assets $N A_{t}^{U}=W_{t}^{U}-V_{t}^{U}-B_{t}$, the current account $C A_{t}^{U}=\dot{W}_{t}^{U}-\dot{V}_{t}^{U}-\dot{B}_{t}$ and the trade balance $T B_{t}^{U}=X_{t}^{U}-\theta W_{t}^{U}$ in all previous periods.

\section{B.2 Collapse of the bubble: the short run.}

Consider now what happens at time $t=t_{0}$ when the bubble collapses. As long as $\sigma<1$, the economy satisfies the following equations:

$$
\begin{aligned}
\dot{I}_{t} & =Z-\alpha \hat{q}_{t}^{-\sigma} \\
\dot{\hat{q}}_{t} & =\left(r_{t}-\frac{g}{\sigma}\right) \hat{q}_{t} \\
r_{t} & =\frac{X_{t}^{1-1 / \sigma} \theta \delta+\theta g \hat{q}_{t} I_{t}-\theta \hat{q}_{t}\left(Z-\alpha \hat{q}_{t}^{-\sigma}\right)}{X_{t}^{1-1 / \sigma}+\alpha \sigma \hat{q}_{t}^{1-\sigma}}
\end{aligned}
$$

This is a dynamic system in $I$ and $\hat{q}$ with a forcing term $X_{t}$. We have one initial condition: $I_{t_{0}}=0$, by assumption. We need a terminal condition on $\hat{q}_{t}$. To find it, consider what happens to the share of commodities in expenditures, $\alpha p_{t}^{1-\sigma} /\left(1+\alpha p_{t}^{1-\sigma}\right)$ over time. From the second equation above, the growth rate of $p_{t}^{1-\sigma}=\hat{q}_{t}^{1-\sigma} X_{t}^{1 / \sigma-1}$ is $(1-\sigma)\left(r_{t}-g / \sigma\right)+g(1 / \sigma-1)=(1-\sigma) r_{t}$, which must be positive eventually (since the interest rate converges to $g / \sigma$ ). Hence the expenditure share must eventually reach $\bar{s}_{z}$, at which point the elasticity of substitution becomes unity. Let's denote $T_{2}$ the time at which this happens, and $\hat{q}_{T_{2^{-}}}, I_{T_{2^{-}}}$the values of the system at that time. Note that $\hat{q}_{T_{2}}$ and $T_{2}$ are also linked by $\alpha \hat{q}_{T_{2}}^{1-\sigma} X_{T_{2}}^{1 / \sigma-1}=\alpha^{\prime}$. Thus, we can parameterize potential equilibrium paths by $T_{2}$.

\section{B.3 Collapse of the bubble: the long run.}

When $t \geq T_{2}$, the economy is now in the unitary elasticity inventory model described in the previous section. The system follows a saddle path dynamics with:

$$
\begin{aligned}
& \dot{I}_{t}=Z-\alpha^{\prime} q_{t}^{-1} \\
& \dot{q}_{t}=\left(r_{t}-g\right) q_{t} \\
& r_{t}=\theta \frac{\delta+\alpha^{\prime}-q_{t}\left(Z-g I_{t}\right)}{1+\alpha^{\prime}}
\end{aligned}
$$

where $q_{t}=p_{t} / X_{t}$. The boundary conditions for that system are $I_{T_{2}}=I_{T_{2^{-}}}$and $\lim _{t \rightarrow \infty} q_{t}=$ $\alpha^{\prime} / Z$. Solving the saddle-path dynamics provides the unique initial value $q_{T_{2}+}$ that is consistent with the equilibrium (see figure 9). 
Lastly, continuity of the price at $T_{2}$ requires that we select $T_{2}$ such that $\hat{q}_{T_{2^{-}}}=q_{T_{2^{+}}} X_{T_{2}}^{(1-1 / \sigma)}$. This completes the characterization of the economy.

\section{Appendix C}

\section{Speculation and Policy}

In this appendix, we expand on Section 5 and analyze the effect of introducing futures markets, as well as the effects of policies aimed at curtailing "speculation".

\section{C.1 Futures}

Let us start by introducing (fully collateralized) future contracts on the $Z$-good. We make two simple and related points: (i) first, the payoff of the strategy that consists in buying the $Z$-good and storing it can be replicated by simple futures positions; (ii) second, in our model, the introduction of futures market has no impact on the equilibrium.

By covered interest parity, the forward rate $f_{t+s}$ is equal to:

$$
f_{t+s}=p_{t} \exp ^{\int_{t}^{t+s}\left(r_{u}+d\right) d u}
$$

Consider the strategy of buying a forward contract at $t$ with maturity $t+s$ and reselling it at date $t+s^{\prime}<t+s$. The payoff at $t+s^{\prime}$ is

$$
p_{t+s^{\prime}}-p_{t} \exp ^{\int_{t}^{t+s}\left(r_{u}+d\right) d u} \exp ^{-\int_{t+s^{\prime}}^{t+s}\left(r_{u}+d\right) d u}=p_{t+s^{\prime}}-p_{t} \exp ^{\int_{t}^{t+s^{\prime}}\left(r_{u}+d\right) d u}
$$

which, in net present value, is exactly the same payoff as that of buying one unit of the $Z$-good at $t$, storing it until $t+s^{\prime}$ and then selling it on the spot market at $t+s^{\prime}$. To the extent that there is heterogeneity in the storage cost that agents need to pay to store the $Z$-good, all the inventories will be held by the agents with the lowest storage costs - typically the producers, who can at least partly leave the $Z$-good in the ground. Agents with higher storage costs will prefer to buy future contracts from the producers.

\section{C.2 Equilibrium and policy}

However, the introduction of futures contracts has absolutely no effect on the equilibrium of our economy. Futures do not increase asset supply: every long position is offset by a corresponding short position, and there are no agents with biased beliefs deviating from the prefect foresight 
price-path. As a result, the imposition of a tax on futures trading, or their prohibition, would have absolutely no moderating effect on commodity prices.

In order for a tax to have any consequence in our model, it must affect the agent with the smallest storage costs, which hold the inventories. Thus, let us consider the effect of taxing producers for holding inventories. While in practice this is extremely hard to do since producers are likely to hold most of their inventories underground, it is a useful positive exercise to gauge the potential impact of these type of policies.

It turns out that taxes on the value of inventory holdings are almost isomorphic with the holding cost parameter $d$, except that that under the tax interpretation, the proceeds can be rebated lump sum to the agents at no resource cost. We take the latter route here and let $\tau$ denote the tax rate per unit of value of inventories (that is, the tax per unit of inventory is $\tau p_{t}$

We maintain the assumption that $\sigma=1$ but strengthen the dynamic inefficiency Assumption 1 to:

Assumption $3 g-\tau>\frac{\theta \delta}{1+\alpha}$.

Under Assumption 3, the bubbleless steady state of the economy is now such that the interest rate is given by

$$
r_{t}=g-\tau,
$$

the price grows at rate $g$

$$
p_{t}=\alpha \frac{X_{t}}{Z}
$$

and long run inventories are constant

$$
I_{t}=\frac{1+\alpha}{\alpha} \frac{1}{\theta(g-\tau)}\left[g-\tau-r^{r e f}\right] Z
$$

The long run level inventory function $I(\tau)$ is decreasing with respect to $\tau$ while the price of oil is unaffected since the relative consumption of $X$ and $Z$ goods is unchanged in the long run. However, in the short run, the imposition of a tax $\tau$ lowers inventories and the price of oil which is equal to $p_{t}=\alpha X_{t} /\left(Z-\dot{I}_{t}\right)$.

In summary, a tax on inventories reduces the level of these and succeeds in temporarily depressing the price of the $Z$ good but it does not affect it in the long run. Note also that the tax reduces the equilibrium interest rate and aggravates dynamic inefficiency in the bubbleless equilibrium, at a cost for the economy. The intuition is transparent. A dynamically inefficient economy is characterized by a scarcity of assets. A tax on inventories discourages the accumulation of inventories and hence reduces asset supply. The interest rate has to adjust downward to clear the asset market. ${ }^{55}$

\footnotetext{
${ }^{55}$ Note that the bubbly equilibrium of the economy is not affected by $\tau$. Moreover, if Assumption 3 is violated, then the bubbleless equilibrium becomes identical to that of the benchmark no-inventory economy.
} 


\section{Appendix D}

\section{Declining Inventories}

In this appendix we expand on a remark in Section 5 and analyze formally the consequences for inventory accumulation of allowing the short-run and long-run elasticity of substitution between good $X$ and good $Z$ to differ. In most analyses of commodity price and inventory dynamics, the forward curve for commodity prices plays a central role. In our model, after the shock, the world is deterministic and risk-neutral to that at date $t$, the forward price $s$ periods ahead $f_{t+s}$ is simply the future spot price $p_{t+s}$. In our case, it will prove more convenient to reason in terms of the $\log$-forward curve which trace $\log f_{t+s}=\log p_{t+s}$ as a function of maturity $s$.

The decision to accumulate inventories is determined by a comparison of the slope of the logforward curve $\frac{\dot{p}_{t}}{p_{t}}$ of the price for the $\mathrm{Z}$ good with the level of the interest rate $r_{t}$. The steeper the slope of the log-forward curve for the price of the $\mathrm{Z}$ good, the higher the expected growth in the price of the $\mathrm{Z}$ good, and the more storage is attractive. Similarly, the lower the level of the interest rate, the more storage is attractive. The elasticity $\sigma$ of the demand for the $\mathrm{Z}$ good is a key parameter governing the slope of the log-forward curve. The higher $\sigma$, the flatter the log-forward curve.

Key to our analysis is the basic idea that the short-run elasticity of demand for commodities $\sigma$ is low in the short run but high in the long run. Let us denote by $\sigma^{\text {short }}$ the short-run elasticity and by $\sigma^{\text {long }}$ the long-run elasticity with $\sigma^{\text {short }}<1<\sigma^{\text {long }}$. The switch from $\sigma^{\text {short }}$ to $\sigma^{\text {long }}$ is typically gradual, and potentially governed by a number of time and state dependent factors. If the long-run elasticity $\sigma^{l o n g}$ of the demand for the $\mathrm{Z}$ good is high enough, then inventories will eventually be undone. This is formalized by the following assumption.

\section{Assumption $4 \quad \frac{g}{\sigma^{l o n g}}<\delta \theta$}

This assumption is more likely to be verified, the higher is $\sigma^{\text {long }}$. When it is verified, then the long run steady-state of the economy features no inventories. In the long run steady state, the interest rate is $\delta \theta$. The price of the $Z$-good is given by $\left(\alpha X_{t} / Z\right)^{\frac{1}{\sigma^{l o n g}}}=p_{t}$ and grows at rate a $g / \sigma^{l o n g}$ which is too low to make the accumulation of inventories worthwhile. The share of the $Z$-good in total consumption converges to 0 , and the economy effectively behaves as an economy without commodities.

Turning to transitional dynamics, imagine that the economy enters the region with $\sigma=\sigma^{\text {long }}>$ 1 with positive inventories $I_{t}>0$. The presence of inventories affects both the goods market and the asset market: the total intertemporal supply of the $Z$-good is higher which depresses the price of the $Z$-good $p_{t}$. Asset supply is higher since inventories act as a store of value, resulting in a higher interest rate $r_{t}$. The desire to reduce inventories can be traced back to how those two markets are 
affected, as the following two equations show

$$
\dot{I}_{t}=Z-\alpha p_{t}^{-\sigma} X_{t} \text { and } \frac{\dot{I}_{t}}{X_{t}}-g \frac{I_{t}}{X_{t}}=\frac{1+\alpha \sigma p_{t}^{1-\sigma}}{p_{t} \theta}\left(\theta \delta-r_{t}\right) \text {. }
$$

Hence a process of inventory reduction is initiated and the economy eventually converges to a steady-state with no-inventories. 